TI 2006-042/3

Tinbergen Institute Discussion Paper
Analysis of Environmental Costs of
Mobility due to Urban Sprawl - A Modelling Study on Italian Cities

Chiara M. Travisil,2

Roberto Camagni

Peter Nijkamp

' DIB, Politecnico di Milano;

2 Fondazione Eni Enrico Mattei, Milano;

3 Vrije Universiteit Amsterdam. 


\section{Tinbergen Institute}

The Tinbergen Institute is the institute for economic research of the Erasmus Universiteit Rotterdam, Universiteit van Amsterdam, and Vrije Universiteit Amsterdam.

Tinbergen Institute Amsterdam

Roetersstraat 31

1018 WB Amsterdam

The Netherlands

Tel.: $\quad+31(0) 205513500$

Fax: $\quad+31(0) 205513555$

Tinbergen Institute Rotterdam

Burg. Oudlaan 50

3062 PA Rotterdam

The Netherlands

Tel.: $\quad+31(0) 104088900$

Fax: $\quad+31(0) 104089031$

Please send questions and/or remarks of nonscientific nature to driessen@tinbergen.nl.

Most TI discussion papers can be downloaded at http://www.tinbergen.nl. 


\title{
ANALYSIS OF ENVIRONMENTAL COSTS OF MOBILITY DUE TO URBAN SPRAWL A MODELLING STUDY ON ITALIAN CITIES
}

\author{
Chiara M. Travisi \\ DIG, Politecnico di Milano \\ and Fondazione Eni Enrico Mattei \\ Milano, Italy \\ chiara.travisi@polimi.it \\ Roberto Camagni \\ DIG, Politecnico di Milano \\ Milano, Italy \\ roberto.camagni@polimi.it \\ Peter Nijkamp \\ Free University \\ Faculty of Economics \\ Amsterdam, The Netherlands \\ pnijkamp@feweb.vu.nl
}

\begin{abstract}
A sound empirical and quantitative analysis on the relationship between different patterns of urban expansion and the environmental or social costs of mobility is rare, and the few studies available provide at best a qualitative discussion of these issues. Some recent tentative studies on the metropolitan area of Milan have empirically explored whether different patterns of urban expansion generate different levels of land use and heterogeneous impacts of urban mobility. The results confirmed the expectation that a higher environmental impact of mobility may result from more extensive and sprawling urban development, from recent urbanisation processes and from residential specialisation. The present paper extends the previous empirical analysis to seven major Italian metropolitan areas (namely, Bari, Florence, Naples, Padua, Perugia, Potenza and Turin) in order to corroborate the previous tentative results for the Italian context. The novelty of the present paper is threefold. First, we are interested in exploring the changes that have occurred due to the increased intensity of mobility across a ten-year period, from 1981 to 1991, which corresponds to the Italian economic boom years. Secondly, using an econometric analysis of cross-section data, we consider several metropolitan areas simultaneously, and are therefore able to explore whether there are significant differences in the way the model explains variations in the mobility impact across various Italian urban areas. And finally, we offer a structural interpretation of the causal chain in the explanation of the mobility impact intensity by using Causal Path Analysis as a statistical test framework.
\end{abstract}

Key-words: urban mobility, sprawl, environmental costs, self-containment capacity, causal path analysis

JEL-classification: Q56, R14, R41 


\section{Scoping the Scene}

Among recent phenomena of urban transformation in the European context, urban sprawl is one of the most debated and controversial (EC, 2004). The term sprawl was coined in North America during the second half of the 1960s, when the features, determinants and effects of this peculiar phenomenon of urban development and conversion captured the interest of both researchers and governments and began to be formally analysed (e.g. Real Estate Research Corporation, 1974; Altshuler, 1977; Windsor, 1979). Although many definitions of sprawl have been given, a central component of most definitions - and of most tentative translations of this term $^{1}-$ is the uncontrolled spreading out of a given city, and its suburbs, over more and more rural or semi-rural land at the periphery of an urban area. This involves, in the short run, the conversion of open space into built-up, developed land and, in the medium-run, a long-term exacerbation of some detrimental environmental externalities, which are characteristic of cities.

Differently from traditional urban expansion, this pattern of development is not followed by an increase in the overall population of the city. Migration here is no longer directed from rural toward urban areas but, instead, from the core - more densely populated - towards the periphery of urban settlements, and beyond ${ }^{2}$. If one looks at Europe, towns and cities are expanding outwards into rural areas at a faster rate than their population is growing: a 20 percent physical expansion in the last 20 years with only a 6 percent increase in population over the same period (CEC, 2004). Moreover, at the same time that cities are expanding outwards, many still contain a large amount of derelict, unused land, and a high number of empty properties.

Another extremely significant trait of sprawl is that the process of expansion is typically disordered and unplanned, often leading to inefficient and unsustainable urban expansion patterns. Indeed, with special regard to Europe, there is a widely shared consensus that urban dispersion is, at least in part, the result of a long-lasting normative lack of or, more in general, inadequate or not very far-sighted urban planning policies, which have been unable to guide the direction of the "push and pull" tendencies of European towns and cities over the last twenty years (for a discussion, see Camagni et al., 1998, 2002a). Of course, the factors that have contributed to the success of the dispersed city in Europe are numerous (for a complete discussion, see Gibelli, 1999). Residential preferences concern: the overall worsening of the quality of life in urban areas (high cost of residential accommodation, congestion, air pollution, noise, deterioration of public spaces, etc.); the evolution of individual preferences and taste in favour of single-household dwellings (following the US archetype); the displacement from central locations of residential use in favour of service activities; the higher costs of real-estate re-designation in central areas compared with extra-urban locations; and, often, less stringent city planning and institutional constraints in the periphery. The same goes for economic activities: increased diffusion of back-office activities irrespective of accessibility economies; poor accessibility of central areas by motorised private transport modes; and increasing fiscal and administrative fragmentation are all contingent elements that have contributed to the success of sprawling patterns of urban expansion.

Today, the European Commission recognizes urban sprawl as the most urgent of the urban design issues, as it leads to green space consumption, high cost of infrastructure and energy, increased social segregation and functional land use divisions, which reinforce the need to travel and increase dependence on the private motorised transport model, leading in turn to increased traffic congestion, energy consumption and polluting emissions (OECD, 2000; CEC, 2004).

\footnotetext{
${ }^{1}$ Among others: périurbanisation, ville éclatée, desserrement urbain, città diffusa, dispersione urbana.

${ }^{2}$ To some extent, this is one of the reasons why some commentators have defined the phenomenon of sprawl as an 'escape' from concentration and from the drawbacks of living in more compact and densely- populated areas.
} 
The favoured vision of high density, mixed-use settlements with no brownfields and empty property, and planned expansions of urban areas rather than ad hoc urban sprawl, has been reinforced in each EC policy document on urban development starting with the "Green Paper on the Urban Environment" (CEC, 1999) ${ }^{3}$. Since then, a number of community initiatives on urban design has been implemented ${ }^{4}$. Nevertheless, additional efforts are still needed to achieve widespread sustainable urban design able to fulfil such shared objectives, and concrete initiatives at national level ought to follow the current acknowledgement of the 'dark side' of urban sprawl. In this direction, the emphasis of the debate is on the need to ensure the adoption of a long-term strategic land-use planning systems, with environmental impacts identified and minimised, able to reverse the tendency that, in the previous decade, have often seen urban development as un unplanned process leading to unsustainable expansion. The focus of the proposed solutions should be specific to the case. In fact, as each town and city is unique, it is not for our purpose to set a standard system for making land use decisions, neither to define the "ideal" settlement pattern. However, the Commission is exploring the possibility of identifying guidelines on "high density" and "mixed used" new developments, the integration of green space, retrofitting urban areas to improve their sustainability, or the continuity of the urban fabric.

Research, exchange of experience and promotion of best practice on urban land issues is therefore of particular importance and highly recommended to attain insights for policy actions. In particular, a starting point should be the identification of the actual state of sprawl-driven negative externalities in towns and cities, and their costs. Next, the identification of the causeeffects relationships that have favoured over time the phenomenon of urban sprawl should take place as well. We are facing in fact a phenomenon that is driven by a number of heterogeneous components - historical, cultural, social, economic, structural - which interact in space, each playing different roles depending on local conditions.

The possibility to monitor the impacts generated by urban sprawl over time and space, as well as to make clearer which are its major determinants is, therefore, an important prerequisite to prepare a solid background for the definition of effective national, regional and/or local urban environment strategies. This is particularly true for Europe, compared with North America, not

\footnotetext{
${ }^{3}$ The EU Expert Group on the Urban Environment was established in 1991; the Sustainable Cities Project was launched in 1993 with the aim of promoting new ideas on sustainability in European urban settings, fostering exchange of experience, disseminating good practice concerning sustainability at the urban level and formulating recommendations for the EU institutions. In 1996, the EU Expert Group produced a major report on "European Sustainable Cities" in support of the local Agenda 21 process. In 1997, the Communication "Towards an Urban Agenda in the European Union" (CEC, 1997) launched efforts to create a thematic strategy on the urban environment, and in 1998 the Communication on "Sustainable Urban Development in the European Union: a Framework for Action" (CEC, 1998) for the first time took a real sustainable development approach with four main interdependent policy objectives: i) strengthening economic prosperity and employment in towns and cities; ii) promoting equality, social inclusion and regeneration in urban areas; iii) protecting and improving the urban environment towards local and global sustainability; and iv) contributing towards good governance and local empowerment. In 2001, the EU Expert Group produced the report "Towards more sustainable urban land use: advice to the European Commission for policy and action". On a wider level, Article 6 of the Treaty places sustainable development at the very core of the EU policies and actions, as stated in the 2001 Communication "A Sustainable Strategy for a Better World: A European Strategy for Sustainable Development" (CEC, 2001).

${ }^{4}$ The European Spatial Development Perspective (ESDP, 1999), which explicitly addressed the question of how to control the physical expansion of towns and cities, was adopted on a voluntary basis by all the Member States in 1999. After that, a number of actions was implemented. To mention some: the European Spatial Observatory Network (ESPON) programme implements and coordinates research in spatial planning, putting in place a framework for collecting and analysing spatial data; the URBAN II initiative supports mixed use and environmentally-friendly brownfield redevelopment, involving reduced pressures on greenfield development and urban sprawl. INTERREG has offered similar opportunities. In addition, the Community supports different research projects related to the revitalisation of city centres and neighbourhoods, the restoration and reuse of contaminated and brownfield sites, the sustainable retrofitting of urban areas such as large housing estates, and strategies to reduce urban sprawl based on the integration of land use and transport planning.
} 
only because of an undisputable scientific delay of about ten years, but also because Europe presents a very much scattered puzzle of territorial conditions, which vary from country to country, region to region and, even, city to city. Major research challenges can be summarised as follows:

i. to qualify and quantify collective costs attributable to diffuse and scattered patterns of urban development over time and space, with the intent of drawing attention to contingent trends and tendencies, as well as to likenesses among different cities as a basis on which to share experiences;

ii. to achieve a comprehensive assessment of the determinants of urban sprawl with the aim of setting priority requirements and, thus, a ranking of priority management actions;

iii. to analyse the effects of past urban planning policies to enhance feedback processes and the definition of good practice for sustainable urban planning.

The focus of the present paper is on points i) and ii), with particular emphasis on the connections between sprawl and the impacts of urban mobility. With respect to this, sound empirical and quantitative results on the collective costs of sprawl are still partial. It is indeed not straightforward to measure the environmental externalities related to the phenomenon of sprawl, especially due to the difficulties of finding sound and reliable performance indicators ${ }^{5}$. Even more challenging is the analysis of the determinants of urban sprawl, especially if one starts from the stance that more perspicacious analyses ought to focus on a local territorial level.

Among the many studies available concerning the European context ${ }^{6}$, there is one particular qualitative comparative analysis of the pros and cons of different urban growth patterns by Breheny et al. (1993) which offers suggestions and recommendations for urban planning actions, set at various administrative levels, but lacks relevant results on the preferable urban growth mode. Camagni et al. (2002b) perform a tentative empirical quantitative analysis on the metropolitan area of Milan, aimed at establishing whether different patterns of urban expansion generate different levels of land consumption and heterogeneous impacts of urban mobility. In particular, the study provides the first insights on whether there is any significant correlation between variables describing the form of urban expansion and the impact of urban mobility, as an indicator of the pressure on the quality of everyday life in metropolitan areas and on the urban environment, with the aim of providing a basis for orienting future planning policies. A mobility impact analysis based on commuting data referring to 1991 was used to capture the level of environmental impact of mobility at the commune level, estimated on the basis of trip time and modal choice. The intensity of mobility impact is then explained by some variables that control for geographical, socio-economic, morphology and transport efficiency factors. The results of the analysis confirm the expectation that a higher environmental impact of mobility is associated with more extensive and sprawling urban development, more recent urbanisation processes and

\footnotetext{
${ }^{5}$ At a local level, the European Commission has recently provided a set of urban environmental indicators, useful to provide a focus for establishing initial policy and action plans, as well as for communicating locally to citizens and to raise the general level of awareness of key urban environmental indicators, which can be used on a voluntary basis (European Common Indicators, ECI www.sustainable-cities.org/indicators/index.htm). Although this includes interesting parameters - such as local mobility and passenger transportation, or the availability of local public open areas and services - the level of detail employed is still insufficient to cover comprehensively all of the issues related to sprawl.

${ }^{6}$ It is not the purpose of this paper to provide an extensive analysis of the North America experience, which exhibits uncomparable administrative, institutional, territorial and suburbanisation features with respect to the European scene. Nevertheless, it is worth noticing that nowadays the great majority of empirical studies on the collective costs of mobility, relate mostly to North America. Yet, results show a significant correlation between different forms of urban development and collective costs, which appear to be higher for less dense development (Ewing et al. 2002, Cervero and $\mathrm{Wu}, 1996)$.
} 
residential specialisation. The same procedure is used in two subsequent studies on the urban areas of Brescia (Camagni et al., 2002a, 2002b) and Bologna (Musolino and Guerzoni, 2003), both referring to the year 1991.

More recently, Salatino (2004) follows the methodology of Ewing et al. (2002) and provides for the Italian regions a static analysis of the univariate correlation between an aggregate indicator of spatial dispersion and a number of parameters that capture some costs attributable to sprawl, with special focus on the private costs of mobility (e.g. household petrol consumption, household transport expenditures, and so forth). Salatino (2005) proposes a similar static analysis at the national level for 11 EU countries, including Italy, and a Path Analysis exercise to find causal relationships among the variables analysed. Both analyses show a positive and significant correlation among parameters controlling for urban dispersion and transport costs, overall providing further indications of the fact that more dense urban forms are accompanied with higher costs of mobility.

In the present paper, a local level focus is adopted and an empirical quantitative procedure similar to the one employed by Camagni et al. (2002b) is extended to seven Italian urban areas: namely, Bari, Florence, Naples, Padua, Perugia, Potenza and Turin ${ }^{7}$.

With respect to the previous studies, the novelty of the present study is threefold. First, the analysis is dynamic and explores the changes that have occurred to the intensity of the mobility impact across a ten-year period, from 1981 to 1991. This is a relevant decade to focus on when studying the Italian context, for a number of reasons: it corresponds to an overall 'deregulation' period that is thought to have promoted, indirectly, the unprecedented success of diffuse urban development patterns; and it coincides with an important economic boom, which led to new practice of private mobility.

Secondly, using multivariate cross-section regression analyses, we consider several urban areas at once, therefore being able to explore whether there are significant differences in the way the model explains variations in the mobility impact across various "prototypes" of Italian urban areas. Cities have, in fact, been selected to provide a representative picture of metropolitan and polycentric Italian urban agglomerations, located in the North, Centre or South of Italy (see Figure 1). The paper attempts, on the one hand, to find empirical evidence of the increasing collective impact of urban mobility, and on the other to figure out whether factors expected to influence the intensity of mobility impact do vary as the city of concern varies or, instead, whether the results are valid and sound for all the Italian cities analysed. This is a very important point for future research, which can help to give an indication of what ought to be the level of analysis to be preferred for studying the negative effects of urban sprawl on mobility, and their explanatory factors. Available studies, in fact, propose either national, regional or local level analyses, often disregarding whether the impacts of sprawl are actually traceable and measurable at higher levels than the local one. In particular, the urban scale to which empirical analyses and case studies should apply remains uncertain.

\section{***** Figure 1 about here $* * * * *$}

Finally, we propose a conceptual interpretation of the causal chain in the explanation of the mobility impact intensity and we test it using Causal Path Analysis (CPA). Differently from Salatino (2005), which uses Path Analysis as an exploratory tool through which to highlight, by

\footnotetext{
${ }^{7}$ Each urban area is a province (from the administrative point of view), and it includes a number of communes within its borders. Overall, more than 700 communes are analysed (see Figure 1).
} 
means of an inductive process, incidental correlations among variables, Path Analysis is used here to test an a priori defined conceptual causal model on the impacts of mobility.

The remainder of the paper is organized as follows. In Section 2 we present the conceptual underpinnings of the development of our (commuting) mobility impact model and describe our hypotheses concerning the reasons for heterogeneities in the intensity of mobility across cities. In Section 3, we present the results of a dynamic analysis of the intensity of the mobility growth over the decade 1981-1991. Next, the determinants of mobility in relation to urban sprawl are statistically analyzed in Section 4. Then, Section 5 presents and discusses the main findings of our empirical multivariate cross-section regression analyses. In Section 6, a conceptual interpretation of the causal chain in explaining the impact of mobility is proposed and empirically tested. Finally, Section 6 provides conclusions and recommendations for future research.

\section{Analysis of the Impact of Mobility in Italy: A Mobility Impact Index}

Many studies on urban sustainability show that the demand for mobility is an important contributor to the environmental impact of urban dynamics, but, so far, empirical evidence and a systematic quantification of the intensity of this phenomenon are still lacking in the European context and are only partial at the Italian level. The first research question addressed in this paper is, therefore, to measure the intensity of urban mobility at local level, for a group of seven Italian urban areas representative of metropolitan and polycentric urban agglomerations located in the North, the Centre or the South of Italy. Previous results by Camagni et al. (2002a, 2002b), Musolino and Guerzoni (2003) and Salatino (2004) show, for the Italian context, that urban settlements characterised by sprawling patterns of development are associated with a higher demand of urban mobility and higher environmental impacts than more compact ones.

An additional question concerns the dynamic of the demand for urban mobility and the related collective costs for the Italian context. In particular, as we move from the 1981-1991 commuting data, we expect to observe an overall increase in the intensity of the impact of urban mobility, caused by the progressive replacement of diffuse with more dense urban development patterns, and by a change in individual preferences for alternative transport modes towards private mobility.

How can urban mobility be captured? For Italy, the lack of reliable mobility data entails a methodological and operational problem. As far as mobility is concerned, we use the only reliable data available at the local (commune) level, i.e. the journey-to-work data recordered in the 1981 and the 1991 Census for each active resident. These data are disaggregated by mode into 6 categories ${ }^{8}$ and, within each mode, by the time taken: up to 30, 31-60, over 60 minutes.

As trip length in terms of distance is not recorded in the Census, a drawback of this approach is that it is not possible to link trip duration and length and, therefore, it is not possible to distinguish between the effect of distance and the effect of vehicle speed and traffic conditions. Another limitation concerns the nature of the available data, which account only for one segment of urban mobility (commuting), disregarding all the non-systematic aspects of mobility. Being aware of the existing data limits, we employ - as in Camagni et al. (2002b) - journey-to-work data to develop a mobility impact index.

\footnotetext{
${ }^{8}$ The categories considered are: walking or other soft means; bus; car driver; motorcycle; car passenger; train, tram or metro.
} 
From the data on travel modes and the time length of commuter trips (direction outside or within each municipality), an indicator of the environmental cost of mobility is created. As the environmental pressure of mobility is strictly related to mode and time length, a weighted index of pressure is therefore defined for 18 different combinations of mode and time, according to the structure of the available data.

The matrix of weights for time and mode, applied to each commuting trip to capture its level of environmental pressure, is described in Table 1, and it is based on two main assumptions:

- For any given mode, the impact of a trip per unit of time decreases with the trip length, according to various kinds of simple, but not trivial, evidence: gas emissions and pollution generated by vehicles are higher at the beginning of the trip; traffic fluidity increases outside urban areas; train stops are fewer on longer journeys, etc.

- Set conventionally at 1.00 per passenger per minute, the weight of the trip by car, the weight of the other various modes for a given duration is, respectively: $1 / 3$ for motorcycle and bus; $1 / 5$ for rail trips and transported passengers; zero for pedestrians or bicycle trips and passengers (this latter weight is justified by considering that the possible lengthening of a journey due to the presence of the passenger is already absorbed by the length of the journey travelled by the driver).

Using the values in Table 1, the commuters recorded in the Census are transformed into 'Equivalent Impact Commuters' (EIC). Given the $k$ th municipality, the intensity of the mobility impact, $I_{k}$, can be estimated as the ratio between the EIC and the actual outward commuters, as follows:

$I_{k}=\frac{\sum_{i j} m_{i j} w_{i j}}{\sum_{i j} m_{i j}}$

where $m_{i j}$ is the number of commuters moving within the $k$ th municipality plus the number of outward commuting trips generated in the $k$ th municipality for the $i$ th travel mode and the $j$ th trip time class; and $w_{i j}$ is the weight assigned to the $i$ th travel mode and the $j$ th trip time class (see Table $1)$.

A shortcoming of this approach relates to the definition of the weight matrix that, as it is now, is not linked to any physical impact dimension and, thus, provides a relative rather than an absolute measurement of the urban mobility impact. On the other hand, a big advantage of this methodology compared with to other more direct indicators of environmental impacts is that it refers directly to the demand of urban mobility generated in each municipality as a consequence of its settlement pattern, rather than referring to some other mobility effects, which can often originate from other municipalities 9 .

The following sections discuss the dynamic of the mobility impact index in the Italian context during the decade 1981-1991, and provide a multivariate analysis of factors explaining the intensity of the mobility impact across Italy, relating to 1991.

\footnotetext{
${ }^{9}$ To improve the methodology, we are now trying to redefine the weight matrix on the basis of gas emission factors related to travel modes and trip time.
} 
***** Table 1 about here $* * * *$

\section{Dynamics of Mobility Impact During 1981-1991}

Before exploring the determinants of the intensity of mobility, we analyse the distribution of the mobility impact index across the seven urban areas (province) of concern and its variation during the period from 1981 to 1991. As explained earlier, during this decade Italy experienced a period of planning 'deregulation' and intense economic growth, two factors that have certainly significantly contributed to the diffusion of sprawl in this country, traditionally characterised by densely populated and well-structured cities. It is therefore interesting to follow the growth in the demand of urban mobility during that period, in consideration of this process of development and modernization, and the consequent increase in income level and change in mobility caused by new tendencies in individual habits and behaviour.

This analysis is performed here at different levels, so that we look at: i) the average impact within each province (considered in a first approximation as the urban commuting area); ii) the average impact of the main city within each province (i.e. the chief town); and iii) the average impact of minor towns located within each province. This allows us to take into account the fact that, within a given province, the dynamics of both socio-economic and spatial conditions during the period 1981-1991 can be significantly different for minor towns.

Figures 2 and 3 show, respectively, the distribution of mobility impact and plots reporting mean, minimum and maximum values for subgroups (based on geographical location and level of polycentricism) for 1981 and 1991. Table 2 provides descriptive statistics of the mobility impact index for 1981 and 1991 at the province level, whereas Table 3 shows the average values and the percentage rate of increase of the impact for the provinces, their chief towns and minor towns.

If we look at absolute values in Table 2, a first result is that the impact of urban mobility decreases as one moves from Northern to Southern Italian regions, as one would expect given the higher income level of northern Italian area, which normally favours the diffusion of motorised private travel means (Kockelman, 1995). The highest impact value refer to Turin, and this is not surprising, as this is the 'land' of the main Italian car producer, Fiat. Nevertheless, the positive trend in the intensity of the mobility impact over the decade 1981-91 characterises all the urban settlements considered, and it is higher for those areas located in the Southern Italian regions, Bari and Potenza in particular. The increase ranges from a minimum of 14.8 percent for Turin to a maximum of 37.3 percent for Potenza (Table 3). Interestingly, with the exception of Turin and Padua, the minor towns experienced a higher percentage increase in the impact of mobility than the chief cities.

A second result is, therefore, that urban mobility has increased noticeably across the whole Italian peninsula for reasons that go beyond the increase of the Italian population, which on average has not exceeded the 5.3 percent points. A thorough analysis of the reasons for such an increase lies outside the scientific aim of this paper and would require an investigation on how the socioeconomic characteristics of a given urban settlement have varied during this time span (e.g. household income, transport networks and infrastructures, changes in production factors and job markets, etc.). Without entering into the detail of this discussion, it suffices to say that among the main drivers of such a tendency, the literature indicates, for Italy, the increasing demand for urban mobility, together with a shift of individual preferences towards private mobility motivated, to some extent, by the higher income level that has made the car market accessible to wider groups of 
citizens, as well as by the lower competitiveness of public compared with private transport modes (Lattarulo, 2003).

The change in individual preferences towards private travel modes is confirmed by the results shown in Table 4, which indicates that, during the decade 1981-1991, the distribution of commuters by travel modes has changed in favour of private transport, with a particularly relevant increase in the use of the private car. Such increment ranges from a minimum of 9 percent (Naples), to a maximum of 14 percent (Turin and Padua). At the same time, other private soft modes have been abandoned, and the incidence of the use of public transport has also decreased, especially the use of the public bus. As the weight matrix used to compute the mobility impact index assigns higher impacts to private transport modes (especially car), we observe higher impact values for $1991^{10}$.

\section{**** Figure 2 and 3 about here $* * * *$ \\ **** Table 2 -3 -4 about here $* * * *$}

\section{Determinants of the Mobility Impact: An Exploratory Univariate Analysis}

The hypothesis underpinning this paper is that, within a relatively homogeneous area (in terms of income level and main socio-economic conditions), such as each of the seven Italian urban areas of concern here, the local differences in mobility patterns can be explained, at least to a certain extent, by the typology of urban development that exists in such areas. Thus, the form in which urban growth has occurred and, in addition, its dynamic is expected to influence the intensity of the mobility impact at a local level and its spatial distribution. In particular, the economic literature on this issue suggests that a number of factors might have a role in explaining why urban mobility changes its intensity across various countries and urban areas (e.g. Frank, 1989; McNally and Kulkarni, 1997; Ewing et al., 2002). In particular, we expect that four types of variables might influence the intensity of mobility impact at a local level: geographical, socio-economic, and morphology variables, and variables measuring the accessibility and efficiency of private versus public transport.

The spatial distribution of the indices of impact intensity is examined using an econometric analysis to ascertain whether there are significant correlations with any of the selected independent variables that describe the characteristics of a given urban settlement. All regression variants refer to 1991 , and the mobility impact index is used as the dependent variable and captures, at the commune level, the intensity of the collective impacts associated with the demand for urban mobility. A few variables controlling for structural and socio-economic differences across urban areas are used as explanatory variables. The relationship is established using least squares estimators. Three classes of explanatory variables are included in the econometric analysis: i) spatial; ii) structural socio-economic; and iii) variables relating to the demand and supply of urban mobility.

Spatial variables include factors that contribute to describing the structural and spatial configuration of a given municipality located within a certain urban area. Among the number of possible parameters, indicators and proxies that can be used to capture the spatial structure of a given town, we consider: a variable that accounts for the distance of a given municipality from the chief town of the urban area to which it belongs (DISTANCE); a variable estimating the incidence of rural landscape within a given municipality (RURAL); and the overall city dimension (POPTOT). In order to describe urban areas according to their sprawling behaviour, we use as a proxy the gross density of the urban settlement (DENSITY). Single measures of urban form based

\footnotetext{
${ }^{10}$ This paper does not investigate the reasons why individual preferences for alternative travel modes have changed.
} 
on density have been extensively used in the international literature (e.g.: Spillar and Rutherford, 1990; Dunphy and Fisher, 1996; Bhat and Singh, 2000). A number of studies have instead considered multiple urban form measures jointly. For instance Frank and Pivo (1994) consider density and land use mix, whereas Kitamura et al. (2001) employ density and an accessibility measure. In this study we include the measure of land use mix among the socio-economic variables that are expected to explain the impact of mobility. In particular we consider: the dynamics of urban growth in the decade under analysis (GROWTH); and a variable explaining the land use functional mix of a given municipality (MIXITE). Finally, the third class of factors includes three variables, which control, respectively, for the accessibility and competitiveness (efficiency) of public transport in a given municipality, and for its self-containment capacity (SHAREPUB, COMPUB, SELFCONT). A detailed description and descriptive statistics of all the explanatory variables used are provided in Table 5 and 6.

With respect to the above-mentioned discussion, our main expectations can be summarized briefly as follows. Population density is expected to have mainly an indirect negative effect on the mobility impact, through its influence on the average trip time of public transport and, hence, on the modal spilt of commuter trips in favour of public transport ${ }^{11}$. Concerning the city dimension, we expect to notice an overall increase in the intensity of mobility moving from smaller to bigger towns, due to the fact that the number of motorised vehicles circulating increases, as well as trip time, and this favours traffic intensity and congestion. Nevertheless, the effect of the city dimension might be compensated by the travel modal choice, whether oriented towards more environmentallyfriendly and public modes, and also by the city density, if high.

The demographic growth rate is expected to show a positive relationship with the intensity of mobility impact. The impact index is expected to increase with the urban dynamism of the commune concerned: in fact, a high population growth rate is generally also associated with the existence of areas of recent expansion, typically scattered all around the older urban conurbation. The literature also gives considerable importance to the residential versus productive attitude of a municipality, in connection with the demand for mobility, as well as with sprawl (e.g. Boarnet and Sarmiento, 1998; Boarnet and Crane, 2001). Sprawl is in fact both a cause and an effect of functional land-use divisions, which reinforce the need to commute and increase dependence on private transport modes. This relationship can be conveniently interpreted as an indicator of the level of functional diversification-integration-segregation, i.e. a kind of a 'functional mix' of each municipality. In particular, we expect to find a negative relationship with the mobility impact indicating that urban mobility becomes more intense as the proportion of employment decreases while the residential character of the area increases.

The relationship between the impact of urban mobility and the efficiency and competitiveness of public transport is also relevant. With respect to this, Camagni et al. (2002b) find empirical evidence that, at least for the metropolitan area of Milan, the mobility impact index is inversely correlated to the share and competitiveness of public transport. Another potentially relevant source of variation concerns the direction of commuters during home-to-work daily trips. In this case, we focus on whether commuters move within the city borders, or whether they are directed outside their own residential town, in connection with the "functional mix" variable. Therefore, we investigate whether what we indicate as the "self-containment" capacity of a given town can help to explain variations in the intensity of the mobility impact. As the literature does not suggest which direction one should expect, our analysis will provide original insights into this matter of concern.

We first analyse univariate relationships between dependent and independent variables using pooled data, after proceeding with the normality test of the independent variables. Figure $4 a-4 j$

\footnotetext{
${ }^{11} \mathrm{We}$ are aware though that, over a certain level and under specific local conditions, high urbanisation density can contribute to the phenomenon of congestion and increase the overall impact of mobility. Nevertheless, the present paper is not addressing this issue.
} 
provides scatter plots, which give preliminary information on the direction of each univariate relationship. Figures 4a-d show that, as expected, RURAL, DENSITY and DISTANCE are negatively correlated with the impact of mobility, and that such correlations are statistically significant. On the other hand, we would expect to observe that IMPACT91 is positively correlated with the city dimension (LogPOPTOT), because the overall demand of mobility is higher in bigger urban areas, but we instead observe a negative correlation. This that can be justified by the fact that bigger towns in our samples are also those more densely built and more mixed in terms of residents and employees and therefore, in principle, less affected by mobility impacts. The graphs in Figure $4 \mathrm{~d}-\mathrm{g}$ refer to socio-economic factors. As expected, GROWTH is positively correlated with IMPACT91; while, in contrast with our expectations, the relationship with the log of MIXITE is also positive. Nevertheless, if one draws scatter plots categorised on the basis of the spatial position of the urban areas (i.e. located in the North, Centre or South of Italy), one can observe negative and significant correlations between the impact of mobility and the functional mix variable. The graphs in Figure $4 \mathrm{~h}-\mathrm{j}$ refer to the relationship between the intensity of mobility impact SHAREPUB and COMPUB and show, in all of the cases, a negative correlation with the impact of mobility.

In sum, the exploratory univariate analysis of the factors determining the impact of urban mobility indicates that our a priori expectations are generally confirmed. Interestingly, some of the univariate relationships that are difficult to capture using pooled data (for instance, the functional mix variable) emerge clearly once we use sub-samples based on the spatial position of urban areas, which suggests that simple univariate correlations can hardly be captured at national level, or that they might produce to misleading results (see Salatino, 2005). In the remainder of the paper, we move from univariate to multivariate relationships, and provide results of different variants of crosssection regression analysis, all referring to 1991.

\author{
***** Table 5-6 about here $* * * *$ \\ **** Figure 4a-4j about here $* * * *$
}

\title{
5. Multiple Regression Variants and Estimation Results
}

The initial step of our analysis is to assess the average effect of explanatory variables, irrespectively of potential heterogeneities across different urban areas. We start therefore by running multivariate regressions using pooled data. Preliminary to this, we check for multicollinearity among independent variables and find no significant redundancy among them.

In our attempt to control for geographical differences, the model includes the distance from the chief town of the related urban area (DISTANCE), and its rural ratio (RURAL). Among the number of socio-economic factors that might play a role in determining the degree of mobility intensity, we focus on the dynamics of urban growth (GROWTH) and the residential versus productive vocation ( $\log$ MIXITE) of a given settlement. We use the density of the urban development (DENSITY) as a proxy of urban form ${ }^{12}$. The model also includes a variable that estimates to what degree urban mobility is (at the commune level) contained within the city borders or, instead, spreads up and beyond the city borders (SELFCONT). We can interpret this as the capacity of a given urban area to

$12 \mathrm{We}$ are aware of the limits of such a procedure, whereas previous research studies have proposed other, more accurate, indicators of urban form (for a discussion and the presentation of synthetic indicators, see Camagni et al. 2002a). To have a better understanding of the spatial distribution of urban settlement within a given area and about its sprawling character, we are at the moment working on the development of graphical indicators of sprawl, based on the methodology proposed by Salvetti (1982). 
contain mobility within its borders, a kind of mobility self-containment capacity, which is expected to be positively related to its productive character. In fact, to some extent, the higher the productive character of an urban settlement, the higher is its capacity to contain commuting within its borders $^{13}$. Coming back to our main argument, we expect SELFCONT to be negatively correlated to the level of mobility impact, for two reasons: on the one side, the average trip times increase moving in a direction that goes beyond the city; second, commuters moving out of their city usually prefer less environmentally-friendly travel means, especially their own car. We find confirmation of this in Table 9, which reports the results of a comparison between the mobility impact indexes calculated, on one side, considering both commuters travelling within the town and those going out of it (a kind of gross mobility) and, on the other side, indexes calculated by considering only the net movements outside of the town. As expected, the intensity of the mobility impact is higher whenever considering the net movements that go outside the city limits, up to 51.3 percent for Potenza.

Furthermore, an important research issue here is to understand what role accessibility and efficiency of public transport can have in curbing the proliferation of urban traffic and congestion. In this perspective we expect that, as the overall competitiveness of public transport increases, commuters' preferences will move towards public transport modes, thus contributing to the reduction of traffic congestion and the intensity of the mobility impact. To capture these dimensions we estimate the accessibility (market share) and the efficiency of public transport calculated as, respectively, the percentage of all trips made with public transport (SHAREPUB), and the ratio between the average trip times with private transport and the average times travelling with public transport (COMPUB).

We begin by analysing the pooled data sample with a simple specification, in which the dependent variable IMPACT91 is modelled as a linear additive function of the usual constant term, the spatial variables (DISTANCE, DENSITY, RURAL), the log of MIXITE, GROWTH, the variables controlling for the direction of urban mobility (SELFCONT), and three dummies controlling for the geographical position of the urban areas (NORTH and SOUTH) and whether they are metropolitan or polycentric (METRO).

In Table 7, Model A shows that the results are consistent with the outcomes of the univariate analyses. All coefficients have the expected sign and are highly statistically significant. Interestingly, SELFCONT contributes to the reduction of the mobility impact. We use the F-test to assess to what extent the heterogeneity of provinces needs to be taken into account using a weighted least squares (WLS) estimator. The pooled regression model can be affected by heteroscedasticity because the mobility impacts refer to different provinces with differing numbers of observations (i.e. different numbers of communes in each province: see Figure 1). We therefore use the number of observations of the underlying province as a proxy to account for the differing sample sizes available for each of the seven urban areas. The sample size of the different provinces ranges between 42 and 316 observations. Table 7 shows that OLS and WLS models provide significant and robust results consistent with our a priori expectations. Finally, Model C includes the variable measuring the share of trips with public transport (SHAREPUB), and a proxy for the efficiency of private versus public transport (COMPUB). The model has a slightly higher explanatory power, and it shows that both regressors are negatively and significantly correlated with the impact of urban mobility. Nevertheless, given the type of data available for the computation of the mobility index, which do not link trip duration with trip length, we are aware that these results might be biased by such underlying omission. The WLS model is omitted as it does not improve the performance of the analysis.

\footnotetext{
13 A regression model of SELFCONT shows that the coefficient of MIXITE is positive and strongly statistically significant for all the cities concerned, with the exception of Potenza and Turin. This suggests that, ceteris paribus, residential cities can contribute to the generation of traffic and congestion more than urban areas with a higher level of 'functional mix'.
} 
Previous results show that the proposed model performs well in explaining the factors that cause heterogeneities in the impact of mobility in different cities. Starting from this, we then proceed by running multiple regressions in cross-section in order to explore the existence of significant differences: i) across single urban areas; ii) across cities located in the North, Centre or South of Italy; and iii) between metropolitan and polycentric urban areas. We use the Wald-test on combined restrictions on model parameters and intercepts across such aggregate samples.

We begin with the analysis of single urban areas. Table 8 reports the results of reduced and full specification OLS and WLS models (A, B, C). Similar to the pooled model, the dependent variable IMPACT91 is modelled as a linear additive function of spatial, structural and mobility variables, with intercepts specific to each province. Overall, the results presented in Table 8 confirm the outcomes of the pooled models (Table 7), even though the significance of coefficients is reduced due to the limited number of observations available for sub-samples based on provinces. The F-test results point to preference for the weighted over the unweighted model. A Wald-test on combined restrictions on the parameters across the different provinces, resulting in seven aggregate samples, shows that the restrictions can be rejected and, therefore, that parameters are statistically different for cities belonging to diverse provinces (urban areas). Likewise, intercepts province-specific intercepts are also statistically unequal.

In particular, major variations relate to the effects that the self-containment capacity and the proportion of agricultural land have in explaining the IMPACT91 variance in different provinces. For such parameters, in fact, coefficients get either a positive or a negative sign. For instance, for SELFCONT, Naples and Turin have negative and significant coefficients, whereas Perugia, Potenza, Florence and Bari have positive and highly significant coefficients not in conformity with our expectation. Another contradictory result is that the proportion of agricultural land favours a higher mobility impact in Naples. Different from the pooled model, the coefficient of SHAREPUB takes on negative and significant values only for the province of Florence and Turin. For Perugia and Potenza, the overall effect of higher rates of commuters travelling on public transport contributes to an increase in the intensity of the impact of mobility, probably due to longer average trip duration.

The main outcomes from these models can be summarised as follows (Table 8). The coefficients of the variable measuring the distance of a given town from the chief city (DISTANCE) are all negative and small in terms of absolute values. For the urban areas of Naples, Padua, Perugia, Potenza and Turin, coefficients are statistically significant and they remain stable across the two models. This suggests that going towards the most external part of the province, municipalities become more autonomous and they behave as a kind of self-contained 'district' that contribute less to urban traffic. An inverse relationship is found between IMPACT91 and the gross population density (DENSITY). Coefficients are small in terms of absolute values, and they are statistically different from zero for Florence and Turin.

An inverse relationship also exists with the variable RURAL, except for the case of Naples. Coefficients are statistically significant for Naples, Perugia, Potenza and Turin, though they are small in absolute values. We can interpret this as an effect of the smaller demand for mobility in areas with higher agricultural land rates. The log MIXITE variable captures the effect of the functional mix of the city on the intensity of the urban mobility impact. In our models, coefficients take on negative but insignificant values for Bari, Florence, Naples, Padua, Perugia, Potenza, Turin. GROWTH, whenever significant, is positively related to the mobility impact. 
It is, however, difficult to interpret the results on the basis of single urban areas. We move, therefore, to a broader level of analysis and run a cross-section analysis on the basis of the geographical location (Table 10), and the level of polycentrism of urban areas (Table 11), using the reduced and usual full model specification.

In Table 10, we can observe that the reduced and the full model of geographic location perform well in terms of explanatory power and significance of coefficients. The Wald-test on combined restrictions on the parameters across North, Centre and South aggregate samples shows that the null hypothesis of equality of regressors and intercepts coefficients across the three sub-samples can be rejected. In this case, the WLS model is not to be preferred to the OLS model and it is omitted in the table. We can argue from these results that the usual specifications can explain the variation in the intensity of the mobility impact at a broader spatial level than the local one, in fact, whenever significant, regressors take on the expected sign for each of the three sub samples, with the sole exception of the SELFCONT variable. SELFCONT coefficients are significant and negative for the Northern and Southern cities, while the coefficient for Central cities is positive. Regarding the effect of the rate of trips with public transport, the coefficient is negative and significant only for the Northern cities, according to the results of the univariate analysis.

Table 11 reports the results obtained with aggregations on the basis of the level of polycentrism. Once more, the Wald-test on combined restrictions on the parameters across polycentric and metropolitan aggregate city samples shows that the null hypothesis of equality of regressors and intercept coefficients can be rejected. The WLS model is not to be preferred to the OLS model, and is omitted. Just as before, whenever significant, regressors take on the expected sign for each subsample. There are, however, some differences in the elasticity of some explanatory variables. In particular, the effect of functional mix, growth rate and density is stronger for towns and cities belonging to a polycentric urban agglomeration, whereas the effect of DISTANCE and RURAL is stronger for metropolitan ones.

***Table 8 -9-10-11 about here $* * * *$

\section{A Causal Chain Model of Mobility Impact}

Moving on from the results presented in the previous section, we now try to enrich our analysis by envisaging a conceptual causal chain in the explanation of the mobility impact intensity, in which the mobility impact is the result of the influence of three main territorial dimensions: structural, economic, and social, as shown in Model 5. In our model, the causal chain originates from the urban settlement's structural features that we interpret as drivers of all other elements in the conceptual chain. In particular, we focus urban form and urban functional mix as major determinants of the self-containment capacity of a given city. The structural dimension of our conceptual model, here represented by the self-containment capacity, is therefore supposed to influence the intensity of the mobility impact through the economic and the social dimension. The economic element is represented by the competitiveness of public vs private transport (in terms of time efficiency), which is a result of the urban settlement's structural features (e.g. urban density, functional diversification, etc). The social element is represented by the modal choice of the city inhabitants, depending on the competitiveness of the public vs private transport that, in its turn, is related to the urban settlement features.

Summarizing the previous discussion, we have that settlements of relatively compact structure and good functional mix will be characterised by higher self-containment capacity, and will 
generate more favourable conditions for public transport competitiveness (in terms of journey-towork time) that, in its turn, will move people preferences towards public transport and, consequently, reduce the impacts of urban mobility.

From this conceptual interpretation, we now attempt to move to the econometric analysis in order to find empirical evidence of it. Before presenting our results, however, it is necessary to note that our causal interpretation of the mobility index derives from a priori explanation of the phenomenon and it can not be derived straight from the statistical estimation process.

In order to test the hypothesis on the causal chain in the explanation of mobility impacts, we employ a methodology based on Causal Path Analysis (CPA) (for an an in-depth description, see e.g. Bollen, 1989). This type of analysis formulates the model as a path diagram, in which arrows connecting variables define the structure of the conceptual framework, and allow the estimation of reaction parameters, i.e. essentially the regression coefficients. The arrow diagram of Figure 6 contains the structure of the causal path that we want to test, which comes from the conceptual model presented in Figure 5. On the right-hand side, we have the endogenous variable (dependent), i.e. the variable that in the end has to be explained by all other variables in the model. The remaining variables in the scheme are exogenous and intermediate variables, where the former are independent (in the sense that their variation is the starting point of the model), while the latter can be influenced by variation in the exogenous variables.

Among various statistical methods, we use the Generalised Least-Square (GLS) method to run the path analysis. GLS allows us to construct a model of linear equations, in which a given variable can behave both as an independent variable (in one equation) and as a dependent variable in a subsequent equation. We can therefore estimate regression coefficients in simultaneous regression models. Under the assumption that each variable has been standardised to unit variance and mean zero, the value assumed by individual parameters represents the order of magnitude of each independent variable in explaining the following dependent variable. The statistical significance of each parameter is given by the values of the T-student test run in parallel to the coefficient estimation analysis.

In the framework of our analysis, three latent variables are chosen, one for each territorial dimension included in the conceptual model, plus three exogenous variables that capture the structural pattern of any given city. DENSITY, MIXITE and RURAL are chosen as exogenous variables, and they describe, respectively, the urban form and function of a given urban area. SELFCONT is chosen to synthesize the general territorial structural dimension; COMPUBB is the economic element of the model; and SHAREPUB estimates individual preferences for public transport, i.e. the social element. The impact of urban mobility is estimated by our Mobility Impact Index. The causal direction of the chain is given by the arrows in Figure 6. The empirical results are presented in Figure 7 with coefficients and T-values in brackets. From this it is easy to see that our conceptual model appears to be corroborated. All parameters are highly statistically significant and have the expected sign. The level of self-containment depends positively on some structural elements represented here by, in particular, residential density, functional mix, and incidence of rural land. From the results presented in Figure 7, we also have a confirmation of the direct link between self-containment and competitiveness of public transport. The related coefficient is positive and highly statistically significant, meaning that, as self-containment capacity goes up, competitiveness of public transport increases, as expected. Moreover, the relationship between modal choice (SHAREPUBB) and the competitiveness of public transport (COMPUBB) is also confirmed to be positive and highly statistically significant. As expected, a greater efficiency of public transport contributes to move individual choices towards public transport, therefore reducing the overall impact of urban mobility. The last link of our chain is indeed negative, meaning that, as expected, ceteris paribus, if individual preferences move towards public transport, we can expect a reduction of the urban mobility impact. 


\section{***** Figure 5-6-7 about here $* * * * *$}

\section{Conclusions}

In Europe, the debate on the social costs associated with sprawling urban patterns is recent, and it calls for empirical evidence of the dimensions of these costs, as, so far, sound empirical and quantitative analysis is still rare. It is indeed a hard task to measure such externalities and, even more, to provide an econometric analysis of the link between the way in which an urban area develops and its effects in terms of collective costs. In this respect, we focus on urban mobility and provide a broad empirical analysis of both the dynamic of urban mobility during the decade 19811991 and the factors determining the intensity of mobility pressure in Italy.

We selected seven Italian urban areas, located in the North, Centre and South of Italy, and used journey-to-work data to compute a mobility impact index at the commune level, for the years 1981 and 1991. The mobility index is based on a weight matrix that associates less environmentallyfriendly mobility behaviours with higher impact scores (Camagni et al., 2002b).

A first result is that - as expected - during this decade, the impact of urban mobility has increased noticeably in the whole peninsula, by up to the 37.3 percent. A regression model shows that the higher rate of use of the private car is one of the main determinants of such an increase.

Subsequently, we describe our hypothesis concerning the reasons for heterogeneities in intensity of mobility impact, and use a cross-section regression framework to test them empirically. The models refer to 1991 data and include variables controlling for structural and socio-economic features of the urban settlement, with a special focus on sprawling character and on the competitiveness and efficiency of public versus private transport. Among the structural factors, whenever statistically significant, urban density, functional mix (economic-residential balance) and rural proportion are negatively correlated to the mobility impact index, while the demographic growth rate is positively correlated. Higher impacts are associated with diffused, sprawling development, residential specialisation, and more recent urbanisation processes.

Finally, we attempt to enrich our analysis by envisaging a conceptual causal chain in the explanation of the mobility impact intensity, which relies on three main components: structural, economic, and social. The three components are represented, respectively, by: the self-containment capacity of a given urban area; the competitiveness of public vs private transport (in terms of time efficiency), modal choice. In our conceptual model, structural factors are drivers of competitiveness of public transport, which, in its turn, influences people's preferences for alternative travel modes. We tested such a causal relationship using CPA, and found substantial confirmation of this, as all coefficients have the expected sign and they are highly statically significant. The results show that the level of self-containment depends on the structural form of urban development, and in particular on its residential density, functional mix, and proportion of farmland. The results also show a positive correlation between the self-containment indicator and public transport competitiveness; and between public transport competitiveness and travel mode preferences. Finally, CPA shows a negative and statistically significant correlation between an increase in the use of public transport and the intensity of urban mobility. 


\section{References}

Altshuler, A. (1997), Review of the cost of sprawl, JAIP 43, April, 207-209.

Bhat, C.R. and Singh, (2000), A comprehensive Daily Activity-Travel Generation Model System for Workers. Transportation Research A, Vol. 34, No. 1, pp. 1-22.

Boarnet, M.G., Crane, R. (2001), The influence of Land Use on Travel Behavior: Specification and Estimation Strategies. Transportation Research A, Vol. 35., pp. 823-845.

Boarnet, M.G., Sarmiento, S. (1998), Can Land Use Policy Really Affect Travel Behaviour? A Study on the Link between Nonwork Travel and Land Use Characteristics. Urban Studies, Vol. 35, No. 7, 1155-1169.

Bollen, K.A. (1989), Structural Equation with Latent Variables, John Wiley and Sons, New York.

Breheny, M.J., T. Gent and D. Lock (1993), Alternative Development Patterns: New Settlements. HMSO, London.

Burchell, R.W. (1992), Impact Assessment of the New Jersey Interim State Development and Redevelopement Plan, Report II: Research Findings, New Jersey Office of State Planning, Trenton, New Jersey.

Burchell, Robert W., et al. The Costs of Sprawl - Revisited. Transit Cooperative Research Program (TCRP) Report 39 , National Academy of Sciences, Washington, D.C., 1999.

Camagni R., M.C. Gibelli and P. Rigamonti, eds. (2002b), Urban Mobility and Urban Form: the Social and Environmental Costs of Different Patterns of Urban Expansion, Ecological Economics, Vol. 40, pp. 199-216.

Camagni, R., and M.C. Gibelli, eds. (1997), Développement Urbain Durable: Quatre Métropoles Européennes à l'Epreuve, Parigi, DATAR/Editions de l'Aube.

Camagni, R., and S. Lombardo (1999), La Città Metropolitana: Strategie per il Governo e la Pianificazione, Alinea, Florence.

Camagni, R., M.C. Gibelli and P. Rigamonti, eds. (2002a), I Costi Collettivi Della Città Dispersa, Alinea, Florence.

Camagni, R., R. Capello and P. Nijkamp (1998), Toward Sustainable City Policy: an Economy-EnvironmentTechnology Nexus, Ecological Economics, Vol. 24, pp. 103-118.

CEC, Commission of the European Communities (1997), Towards a Urban Agenda in the European Union, COM(1997)197, EC, Brussels.

CEC, Commission of the European Communities (1998), Sustainable Urban Development in the European Union: a Framework for Action", COM(1998), EC, Brussels.

CEC, Commission of the European Communities (1999), Green Paper on the Urban Environment, COM(1999)218, EC, Brussels.

CEC, Commission of the European Communities (2001), A Sustainable Strategy for a Better World: a European Strategy for Sustainable Development, COM(2001)264, EC, Brussels.

CEC, Commission of the European Communities (2004), Towards a Thematic Strategy on the Urban Environment, COM(2004)60, EC, Brussels.

Cervero, R. (1996). Mixed Land Use and Commuting: Evidence from the American Housing Survey. Transportation Research A, Vol. 30, 361-377.

Cervero, R. and Wu, K. (1997). Influence of Land Use Environments on Commuting Choices: an Analysis of Large Use U.S. Metropolitan Areas Using the 1985 American Housing Survey. Working Paper 683. University of California at Berkeley.

Cervero, R., Kockelman, K.M. (1997). Travel Demand and the 3 Ds: Density, Diversity and Design. Transportation Research D, Vol. 2, 199-219.

Dunphy, R.T. and Fisher, K. (1996), Transportation Congestion, and Density: New Insights. Transportation Research Record, No. 1552, pp. 89-96.

ESDP, 1999. Towards Balanced and Sustainable Development of the Territory of the European Union, European Communities, Luxembourg, May 1999

European Common Indicators, ECI, www.sustainable-cities.org/indicators/index.htm

Ewing R., Pendall R., Chen D. (2002), Measuring Sprawl and Its Impact, Smart Growth America, Washington.

Fouchier, V. (2000), Intervenir sur les densités urbaines pour limiter l'usage de l'automobile, La forme des villes: caractériser l'étament urbain et réfléchir à des nouvelles modalités d'action, Collections du CERTU, Lyon.

Frank, J.E. (1989), The Costs of Alternative Development Patterns: A Review of the Literature, Urban Land Institute, Washington DC.

Frank, L.D. and Pivo, G. (1994), Impacts of Mixed Use and Density on Utilization of Three Modes of Travel: SingleOccupant Vehicle, Transit, and Walking. Transportation Research Record, No. 1466, pp. 44-52.

Gibelli, M.C. (1999), Dal Modello Gerarchico alla Governance: Nuovi Approcci alla Pianificazione e Gestione delle Aree Metropolitane, La Città Metropolitana: Strategie per il Governo e la Pianificazione (R. Camagni and S. Lombardo, eds.), Alinea, Florence.

Kitamura, R., Akiyama, T., Yamamoto, T. Golob, T.F. (2001), Accessibility in a Metropolis. Transportation Research Record, No. 1780, pp. 64-75.

Kockelman, K.M. (1995), Which Matter More in Mode Choice: Density or Income? Institute of Transportation Engineers 1995, Compendium of Technical Papers, 844-867.

Lattarulo, P. (2003), I costi ambientali e sociali della mobilità, IRPET, Franco Angeli, Milano. 
McNally, M.G.and Kulkarni, A. (1997), Assessment of influences of the land use-Transportation System on Travel Behavior. Transportation Research Record, No. 1607, pp. 105-115.

Musolino, D., and M. Guerzoni (2003), Città Dispersa e Costi Collettivi: il Caso di Bologna, Scienze Regionali, No. 1/2003, pp. 107-112.

Nijkamp, P. (1994), Roads toward Environmentally Sustainable Transport, Transportation Research, Vol. 28, pp. 261271.

OECD (1995), Reconciling Transportation, Energy and Environmental Issues -The Role of Public Transport, OECD, Paris.

OECD (2000), Managing Urban Growth, DT/Tdpc, Paris.

Real Estate Research Corporation (1974), The Costs of Sprawl: Environmental and Economic Costs of Alternative Residential Development Patterns at the Urban Fringe, US Government Printing Office, Washington DC.

Salatino M. (2004), Dispersione urbana e Costi Collettivi del Trasporto Privato nelle Regioni Italiane, Atti della XXV Conferenza AiSre, Novara, Ottobre 2004.

Salatino M. (2005), La Correlazione tra Forma Urbana e Mobilità nei Paesi UE: un'Analisi Statistica, Scienze Regionali, forthcoming.

Salvetti, A. (1982), I Gradi di Dispersione della Popolazione (x) e di Compattezza degli Insediamenti (P), Rapporto sullo Stato dell'Urbanistica in Italia e sulle Politiche Urbanistiche e Territoriali per gli anni '80 (G. Astengo, ed.), Ricerca Mip-Iuav, Venezia.

Simmons M. (1999), The Revival of Regional Planning. Government Intentions: Local Reality?, Town Planning Review, Vol. 70.

Spillar, R.J. and Rutherford, G.S. (1990), The Effects of Population Density and Income on Per Capita Transit Ridership in Wenster American Cities. Institute of Transportation Engineers 1990, Compendium of Technical Papers, pp. 327-331.

TCRP (1998), The Cost of Sprawl-Revisited, Transportation Research Board, National Research Council, National Academy Press, Washington, DC.

Windsor, D. (1979), A Critique of the Costs of Sprawl, Journal of the American Planning Association, Vol. 45, No. 3, pp. 209-212.

World Health Organisation (2002), Health Impact Assessment of Air Pollution in the Eight Major Italian Cities, WHO, London. 


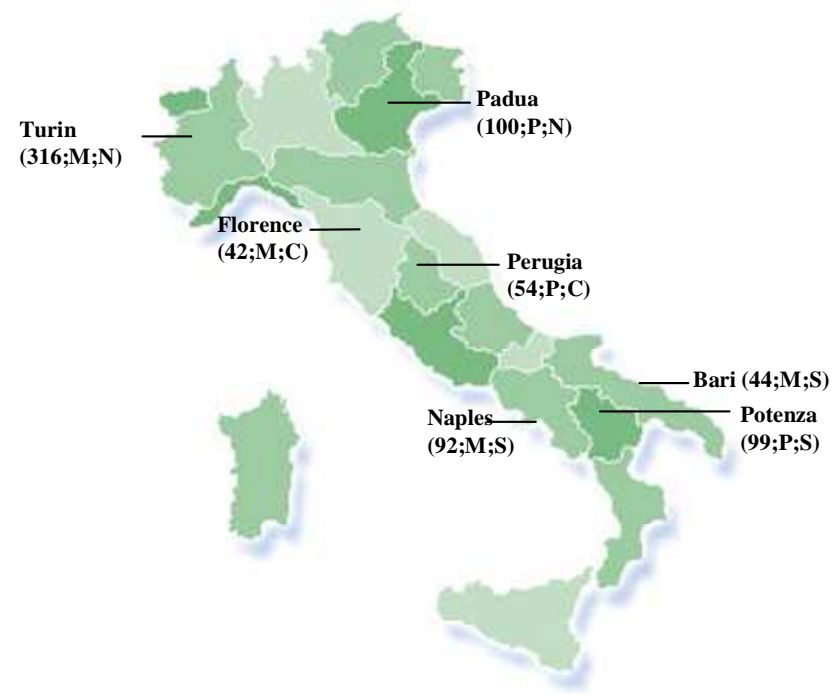

Figure 1: Geographical location and a taxonomy of the urban areas concerned

Notes: The following variables are reported in parentheses: the number of communes in each area, the type of urban settlement in the region (M: Metropolitan; P: Polycentric) and its geographical location (N: North; C: Centre; S: South). Note that polycentrism is measured as the ratio between the population of the chief town of a given urban area (province) and the sum of the population of the ten biggest cities belonging to the province. A given urban area is defined as Metropolitan when this ratio is higher than 0.5, and Polycentric when it is lower than 0.5.

Table 1: Weights by travel time and travel mode.

\begin{tabular}{|c|c|c|c|c|c|}
\hline & Classes of travel modes (ith) & $\begin{array}{l}\text { Weights } \\
\text { for modes }\end{array}$ & & Time $(\min )$ & \\
\hline Classes of trip time (jth) & & & $0-30 \mathrm{~min}$ & $31-60 \mathrm{~min}$ & $>60 \mathrm{~min}$ \\
\hline \multirow{9}{*}{$\begin{array}{l}\text { Average trip time } \\
\text { Weight per time unit } \\
\text { Equivalent trip time }\end{array}$} & \multirow{9}{*}{$\begin{array}{l}\text { Walking or other soft means } \\
\text { Bus } \\
\text { Private car (driver) } \\
\text { Motorcycle } \\
\text { Private car (passenger) } \\
\text { Train, tram, underground }\end{array}$} & \multirow{9}{*}{$\begin{array}{l}0.00 \\
0.33 \\
1.00 \\
0.33 \\
0.00 \\
0.20\end{array}$} & $15 \mathrm{~min}$ & $45 \mathrm{~min}$ & $75 \mathrm{~min}$ \\
\hline & & & 1.20 & 1.00 & 0.80 \\
\hline & & & $18 \min$ & $45 \mathrm{~min}$ & $60 \mathrm{~min}$ \\
\hline & & & 0.00 & 0.00 & 0.00 \\
\hline & & & 0.13 & 0.33 & 0.44 \\
\hline & & & 0.40 & 1.00 & 1.33 \\
\hline & & & 0.13 & 0.33 & 0.44 \\
\hline & & & 0.00 & 0.00 & 0.00 \\
\hline & & & 0.20 & 0.20 & 0.27 \\
\hline
\end{tabular}



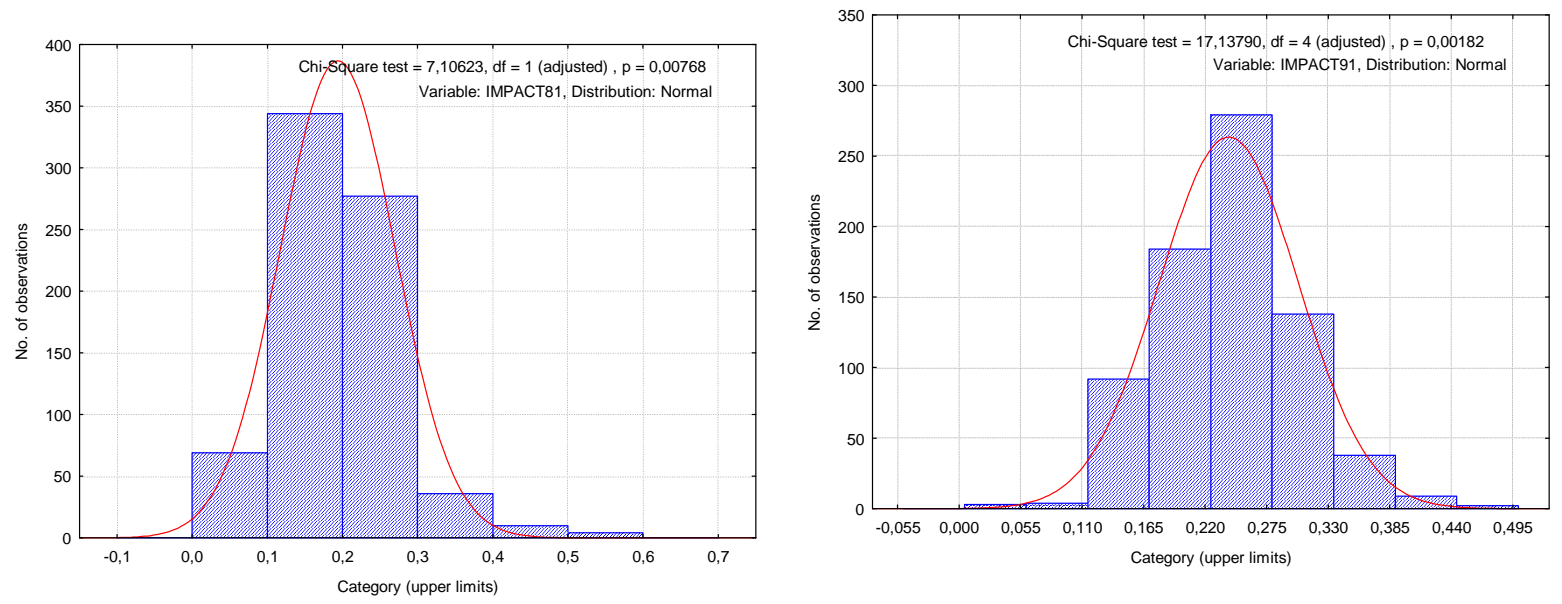

Figure 2: Distribution of the mobility impact index for 1981 and 1991
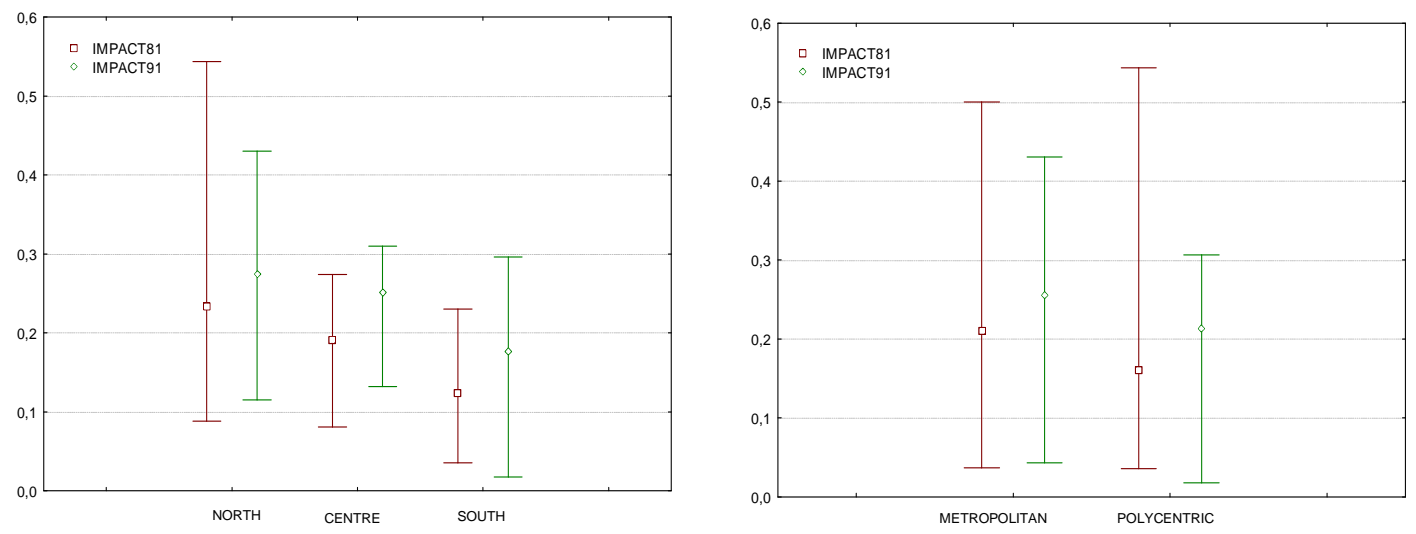

Figure 3: Box-plots reporting mean, minimum and maximum values of the mobility impact index for 1981 and 1991 , for metropolitan and polycentric areas and according to the geographical location. 
Table 2: Descriptive statistics of mobility impact index for 1981 and 1991

\begin{tabular}{lcccccc}
\hline \multicolumn{1}{c}{ Variable } & No.obs. & Mean & Median & Minimum & Maximum & Std. dev \\
\hline \hline IMPACT81 & & & & & & \\
\hline Bari & 44 & 0,105 & 0,102 & 0,067 & 0,146 & 0,021 \\
Florence & 42 & 0,195 & 0,194 & 0,085 & 0,288 & 0,037 \\
Naples & 91 & 0,151 & 0,149 & 0,039 & 0,242 & 0,043 \\
Padua & 100 & 0,198 & 0,178 & 0,123 & 0,572 & 0,089 \\
Perugia & 48 & 0,189 & 0,195 & 0,091 & 0,240 & 0,032 \\
Potenza & 99 & 0,109 & 0,108 & 0,038 & 0,202 & 0,032 \\
Turin & 315 & 0,245 & 0,235 & 0,093 & 0,526 & 0,059 \\
\hline IMPACT91 & & & & & & \\
Bari & 44 & 0,159 & 0,156 & 0,119 & 0,201 & 0,019 \\
Florence & 42 & 0,260 & 0,261 & 0,206 & 0,326 & 0,028 \\
Naples & 91 & 0,189 & 0,190 & 0,045 & 0,312 & 0,042 \\
Padua & 100 & 0,237 & 0,238 & 0,167 & 0,289 & 0,028 \\
Perugia & 48 & 0,244 & 0,245 & 0,139 & 0,323 & 0,030 \\
Potenza & 99 & 0,174 & 0,178 & 0,019 & 0,246 & 0,036 \\
Turin & 315 & 0,287 & 0,282 & 0,121 & 0,453 & 0,049 \\
\hline
\end{tabular}

Table 3: Mean value and rate of increase of the mobility impact index per urban area and time period

\begin{tabular}{|c|c|c|c|c|c|c|c|c|c|}
\hline & \multicolumn{3}{|c|}{1981} & \multicolumn{3}{|c|}{1991} & \multicolumn{3}{|c|}{ Increase rate 1981-91 (\%) } \\
\hline & $\begin{array}{c}\text { (a) } \\
\text { Province }\end{array}$ & $\begin{array}{c}\text { (b) } \\
\text { Chief town }\end{array}$ & $\begin{array}{l}\text { (c) } \\
\text { Other }\end{array}$ & $\begin{array}{c}\text { (a) } \\
\text { Province }\end{array}$ & $\begin{array}{c}\text { (b) } \\
\text { Chief town }\end{array}$ & $\begin{array}{l}\text { (c) } \\
\text { Other }\end{array}$ & (a) & (b) & (c) \\
\hline$\overline{\overline{\text { Bari }}}$ & $\overline{00,105}$ & 0,142 & 0,115 & 0,159 & $\mid 0,181$ & 0,155 & \begin{tabular}{|c|}
33,9 \\
\end{tabular} & 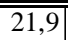 & 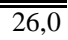 \\
\hline Florence & 0,195 & 0,184 & 0,195 & 0,260 & 0,206 & 0,262 & 25,2 & 10,8 & 25,5 \\
\hline Naple & 0,151 & 0,195 & 0,150 & 0,189 & 0,203 & 0,189 & 20,4 & 3,9 & 20,6 \\
\hline Padua & 0,198 & 0,174 & 0,198 & 0,237 & 0,221 & 0,237 & 16,3 & 21,3 & 16,3 \\
\hline Perugia & 0,189 & 0,199 & 0,189 & 0,244 & 0,240 & 0,244 & 22,7 & 17,0 & 22,6 \\
\hline Potenz & 0,109 & 0,148 & 0,109 & 0,174 & 0,199 & 0,174 & 37,3 & 25,7 & 37,5 \\
\hline Turin & 0,245 & 0,192 & 0,245 & 0,287 & 0,241 & 0,287 & 14,8 & 20,2 & 14,8 \\
\hline
\end{tabular}

Notes:

(a) mean impact value for each urban area (province).

(b) impact value for the chief town of a given province.

(c) mean impact value referring to the minor towns of a given province.

Table 4: Percentage distribution of commuters by travel mode during 1981 and 1991

\begin{tabular}{rrrrrrrrr} 
& & Naples & Turin & Bari & Florence & Padua & Perugia & Potenza \\
\hline \hline \multirow{2}{*}{ Walking or other soft means } & 1981 & $44 \%$ & $29 \%$ & $56 \%$ & $30 \%$ & $37 \%$ & $28 \%$ & $58 \%$ \\
\cline { 2 - 9 } & 1991 & $41 \%$ & $22 \%$ & $45 \%$ & $23 \%$ & $26 \%$ & $21 \%$ & $41 \%$ \\
\hline \multirow{2}{*}{ Bus } & 1981 & $24 \%$ & $25 \%$ & $13 \%$ & $23 \%$ & $17 \%$ & $24 \%$ & $17 \%$ \\
\cline { 2 - 8 } & 1991 & $17 \%$ & $18 \%$ & $10 \%$ & $15 \%$ & $15 \%$ & $17 \%$ & $19 \%$ \\
\hline \multirow{2}{*}{ Private car (driver) } & 1981 & $15 \%$ & $28 \%$ & $17 \%$ & $27 \%$ & $25 \%$ & $32 \%$ & $16 \%$ \\
\cline { 2 - 8 } & 1991 & $24 \%$ & $42 \%$ & $28 \%$ & $37 \%$ & $39 \%$ & $45 \%$ & $29 \%$ \\
\hline \multirow{2}{*}{ Motorcycle } & 1981 & $1 \%$ & $2 \%$ & $2 \%$ & $8 \%$ & $12 \%$ & $6 \%$ & $1 \%$ \\
\cline { 2 - 8 } & 1991 & $2 \%$ & $1 \%$ & $2 \%$ & $11 \%$ & $7 \%$ & $3 \%$ & $1 \%$ \\
\hline \multirow{2}{*}{ Private car (passenger) } & 1981 & $4 \%$ & $7 \%$ & $6 \%$ & $6 \%$ & $7 \%$ & $7 \%$ & $6 \%$ \\
\cline { 2 - 8 } & 1991 & $7 \%$ & $9 \%$ & $10 \%$ & $8 \%$ & $10 \%$ & $11 \%$ & $9 \%$ \\
\hline \multirow{2}{*}{ Train,tram,metro } & 1981 & $11 \%$ & $10 \%$ & $6 \%$ & $6 \%$ & $2 \%$ & $3 \%$ & $3 \%$ \\
\cline { 2 - 8 } & 1991 & $10 \%$ & $8 \%$ & $6 \%$ & $6 \%$ & $3 \%$ & $2 \%$ & $2 \%$ \\
\hline
\end{tabular}


Table 5: Variables list and description

\begin{tabular}{|c|c|c|}
\hline Type of variable & Abbreviation & Definition \\
\hline Dependent: & IMPACT91 & $\begin{array}{l}\text { Average intensity of the impact of urban mobility at commune level. The } \\
\text { impact of mobility is calculated as the ratio between the EIC and the number } \\
\text { of commuters recorded in the Census }\end{array}$ \\
\hline \multirow[t]{8}{*}{ Spatial } & DISTANCE & $\begin{array}{l}\text { Distance }[\mathrm{Km}] \text { between the centroid of a commune and the centroid of the } \\
\text { capital of the province }\end{array}$ \\
\hline & RURAL & $\begin{array}{l}\text { The incidence of rural areas is calculated as the rural area }\left[\mathrm{Km}^{2}\right] \text { over the } \\
\text { total land area }\left[\mathrm{Km}^{2}\right]\end{array}$ \\
\hline & DENSITY & $\begin{array}{l}\text { The gross density of the commune is calculated as the number of residents } \\
\text { over the whole land area }\left[\mathrm{Km}^{2}\right]\end{array}$ \\
\hline & POPTOT & Total number of residents \\
\hline & SUPTOT & Total land area $\left[\mathrm{Km}^{2}\right]$ \\
\hline & NORTH & Takes value 1 if the city is located in the North of Italy \\
\hline & CENTRE & Takes value 1 if the city is located in the Centre of Italy \\
\hline & SOUTH & Takes value 1 if the city is located in the South of Italy \\
\hline \multirow[t]{4}{*}{ Structural } & MIXITE & Ratio between the number of jobs and residents of a commune \\
\hline & GROWTH & Growth rate of the population between 1981 and 1991 \\
\hline & METRO & Takes value 1 if the urban area is metropolitan \\
\hline & POLYC & Takes value 1 if the urban area is polycentric \\
\hline \multirow[t]{3}{*}{ Mobility } & COMPUB & $\begin{array}{l}\text { The relative competitiveness of public transport is calculated as the ratio } \\
\text { between the average time taken for trips made with private transport and the } \\
\text { average time taken for trips made with public transport (the ratio is } \\
\text { multiplied by } 100 \text { for computational reasons). }\end{array}$ \\
\hline & SHAREPUB & $\begin{array}{l}\text { The market share of public transport calculated as the percentage of all trips } \\
\text { made by public transport }\end{array}$ \\
\hline & SELFCONT & $\begin{array}{l}\text { The degree of containment of urban mobility within a given urban settlement } \\
\text { (at commune level) is measured as the ratio between the number of } \\
\text { commuters moving out of the commune, and the number of commuters } \\
\text { moving within and going outside the commune }\end{array}$ \\
\hline
\end{tabular}

Table 6: Descriptive statistics of independent variables, referring to 1991

\begin{tabular}{lrrrr}
\hline Variable & \multicolumn{1}{c}{ Mean } & Minimum & Maximum & Std.dev \\
\hline \hline DISTANCE & 71.78 & 1.00 & 157.00 & 30.91 \\
DENSITY & 5.10 & 0.46 & 9.48 & 1.56 \\
RURAL & 48.99 & 1.77 & 175.15 & 24.23 \\
GROWTH & 2.25 & 55.30 & 69,90 & 10.34 \\
MIXITE & 0.48 & - & 2.34 & 0.29 \\
SELFCONT & 0.36 & 0.01 & 1.00 & 0.16 \\
COMPUB & 35.21 & 3.71 & 174.57 & 18.65 \\
\hline
\end{tabular}




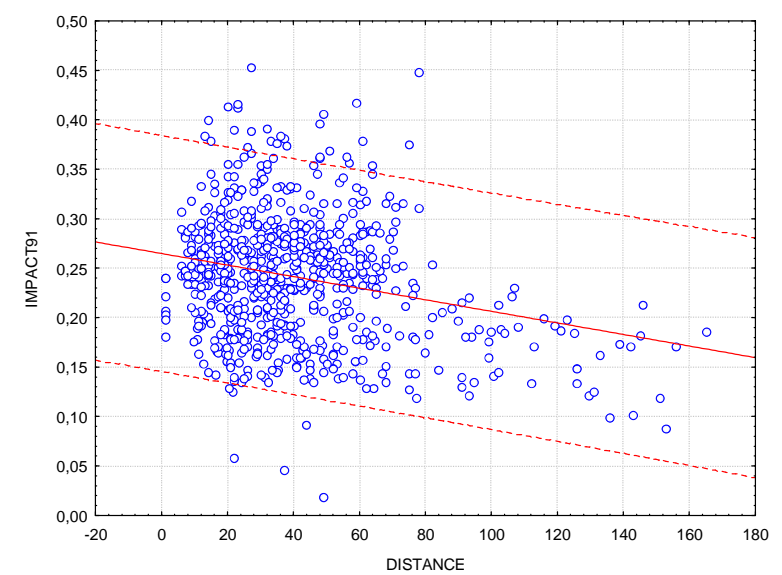

Figure 4a: Scatter plot describing the univariate relationship between IMPACT91 and DISTANCE, with linear fitting and regression bands at 95 percent prediction level.

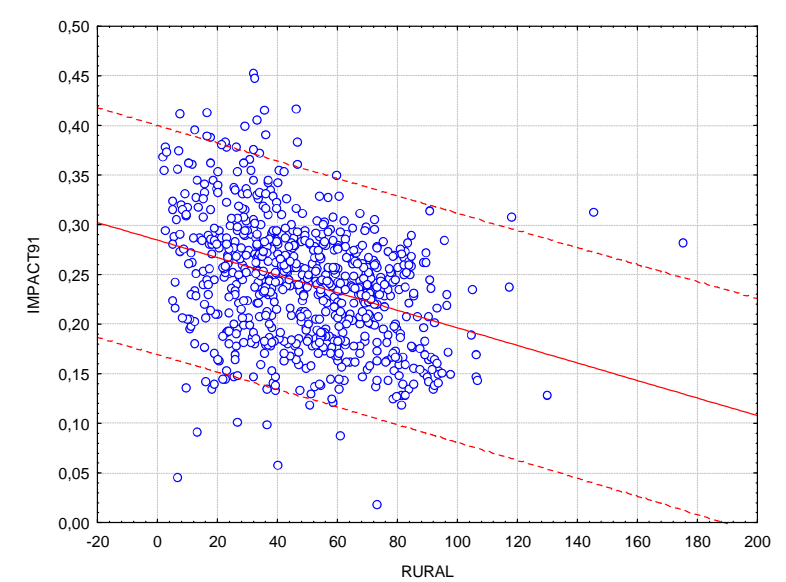

Figure 4b: Scatter plot describing the univariate relationship between IMPACT91 and RURAL, with linear fitting and regression bands at 95 percent prediction level.

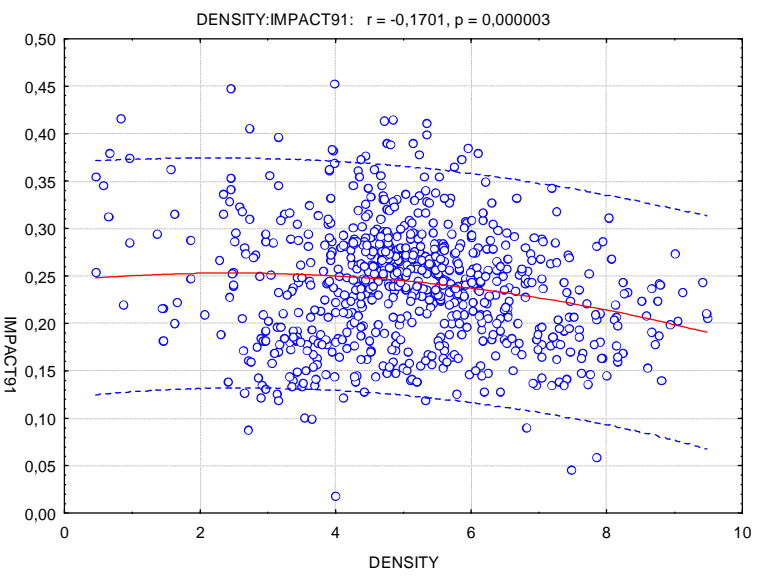

Figure 4c: Scatter plot describing the univariate relationship between IMPACT91 and DENSITY, with polynomial fitting and regression bands at 95 percent prediction level

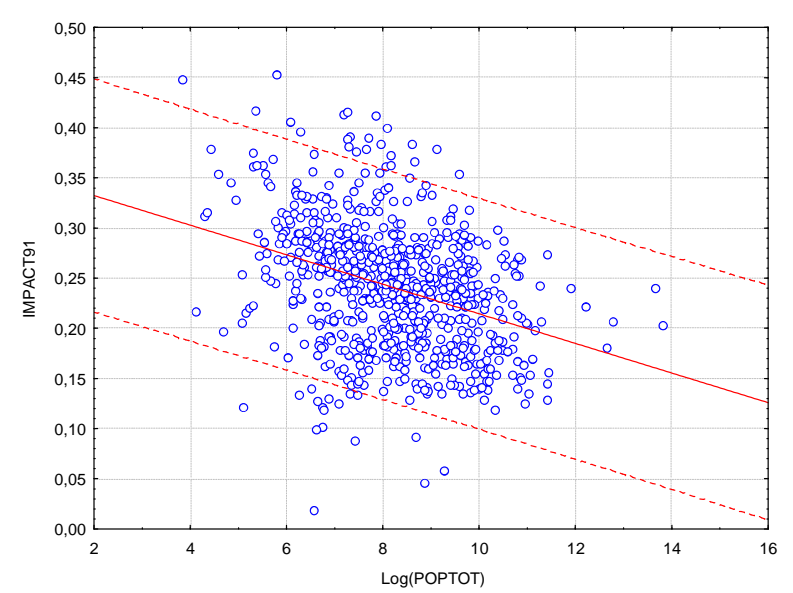

Figure 4d: Scatter plot describing the univariate relationship between IMPACT91 and $\log ($ POPTOT), with linear fitting and regression bands at 95 percent prediction level 


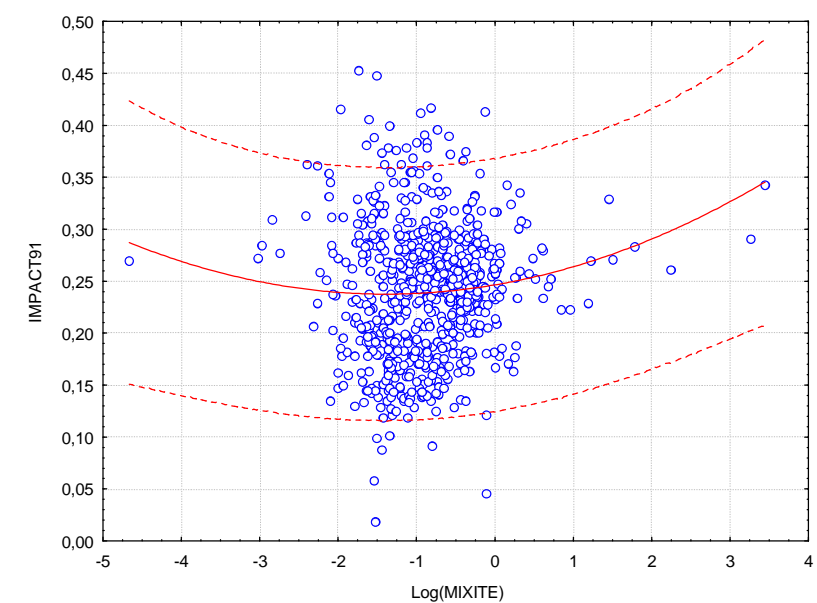

Figure 4e: Scatter plot describing the univariate relationship between IMPACT91 and $\log ($ MIXITE), with polynomial fitting and regression bands at 95 percent prediction level.

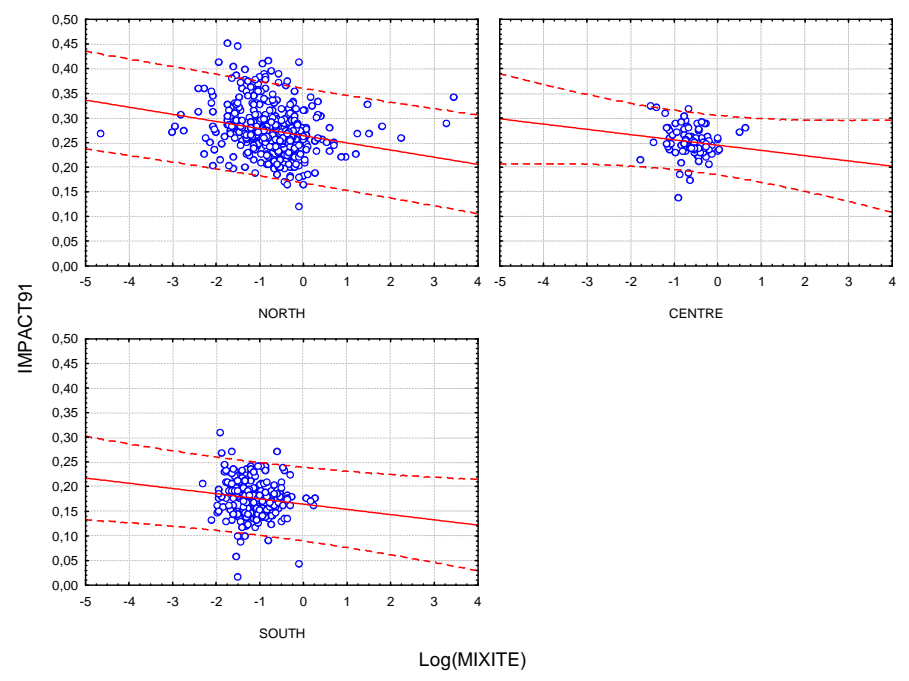

Figure 4f: Scatter plots categorised according to the geographical position of towns, describing the univariate relationship between IMPACT91 and $\log$ (MIXITE), with linear fitting and regression bands at 95 percent prediction level.

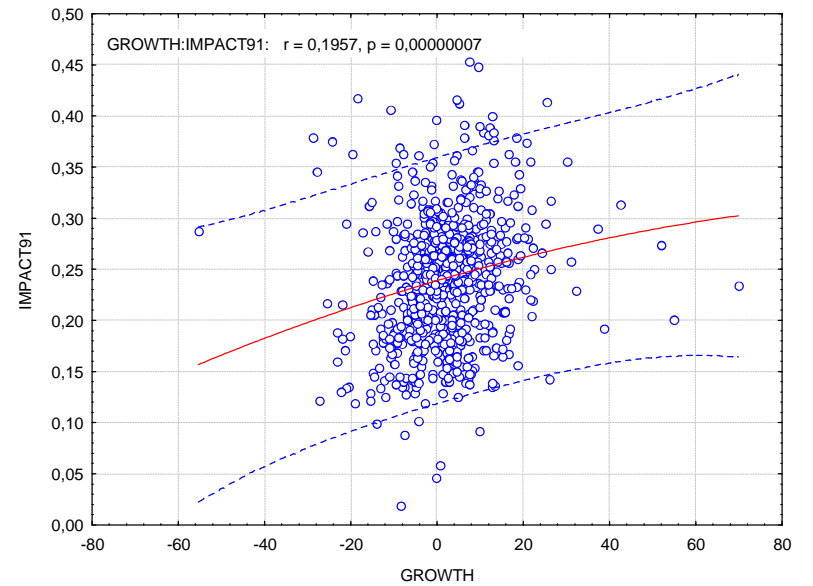

Figure 4g: Scatter plot describing the univariate relationship between IMPACT91 and GROWTH, with linear polynomial and regression bands at 95 percent prediction level. 


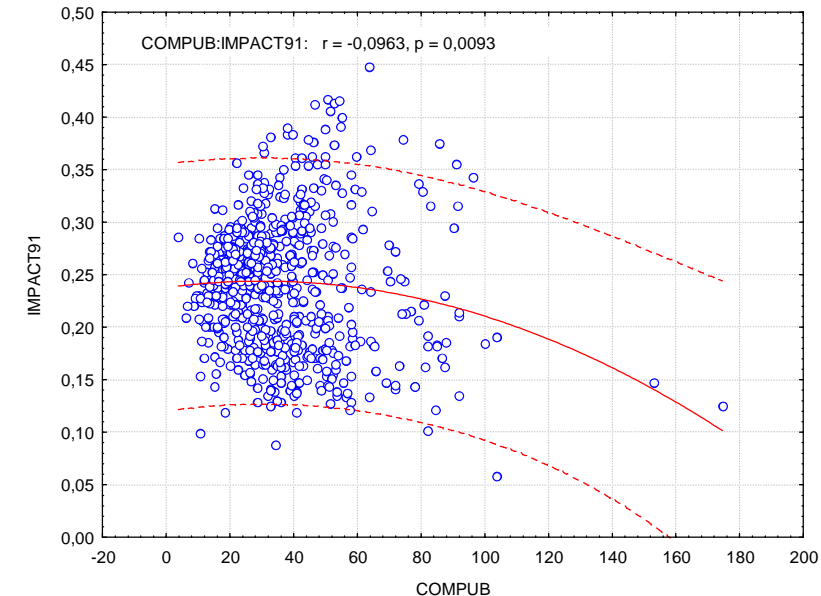

Figure 4h: Scatter plots describing the univariate relationship between IMPACT91 and COMPUB, with polynomial fitting and regression bands at the 95 percent prediction level.

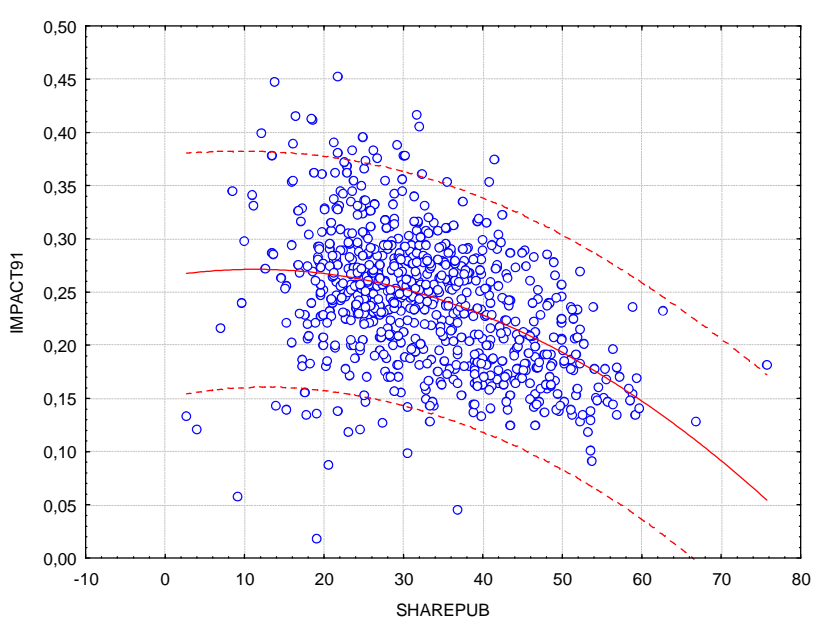

Figure 4i: Scatter plots describing the univariate relationship between IMPACT91 and SHAREPUB, with polynomial fitting and regression bands at the 95 percent prediction level.

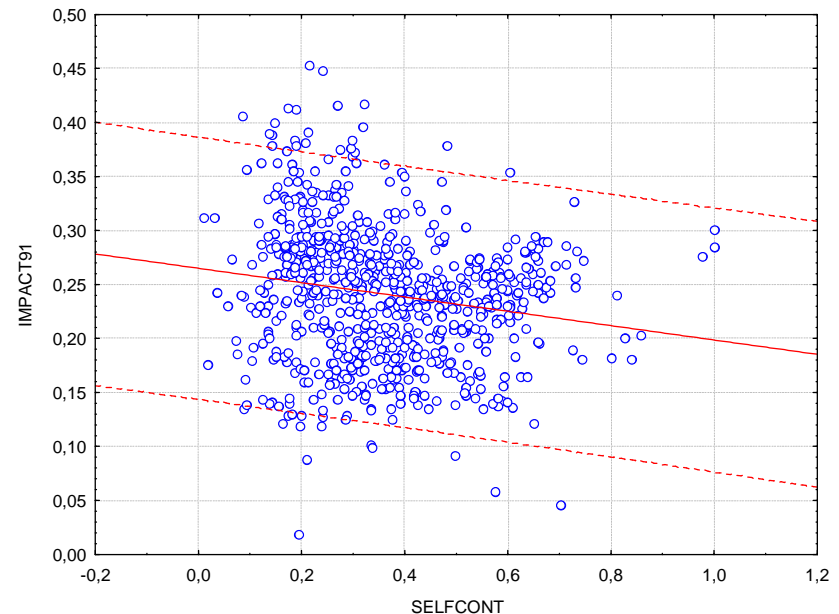

Figure 4j: Scatter plots describing the univariate relationship between IMPACT91 and SELFCONT, with linear fitting and regression bands at the 95 percent prediction level. 
Table 7: Least squares regression analysis of the Mobility Impact Index 1991, using pooled data

\begin{tabular}{|c|c|c|c|}
\hline & $\begin{array}{c}\text { OLS } \\
\text { Model A }\end{array}$ & $\begin{array}{c}\text { WLS } \\
\text { Model B }\end{array}$ & $\begin{array}{c}\text { OLS } \\
\text { Model C }\end{array}$ \\
\hline Dependent variable: & IMPACT91 & IMPACT91 & IMPACT91 \\
\hline \multicolumn{4}{|l|}{ Independent variables: } \\
\hline Intercept $\beta$ & $\begin{array}{c}0.31 * * * \\
(0.01)\end{array}$ & $\begin{array}{l}0.29 * * * \\
\left(0.68^{-02}\right)\end{array}$ & $\begin{array}{l}0.33^{* * * *} \\
\left(0.89^{-02}\right)\end{array}$ \\
\hline DISTANCE & $\begin{array}{c}-0.43^{-03 * * *} \\
\left(0.66^{-04}\right)\end{array}$ & $\begin{array}{c}-0.31^{-03} * * * \\
\left(0.58^{-04}\right)\end{array}$ & $\begin{array}{c}-0.44^{-03} * * * \\
\left(0.65^{-04}\right)\end{array}$ \\
\hline DENSITY & $\begin{array}{l}-0.39^{-05 * *} \\
\left(0.13^{-05}\right)-\end{array}$ & $\begin{array}{l}-0.21^{-05 *} \\
\left(0.11^{-05}\right)-\end{array}$ & $\begin{array}{c}-0.40^{-05} * * * \\
\left(0.13^{-05}\right)-\end{array}$ \\
\hline RURAL & $\begin{array}{c}-0.51^{-03 * * *} \\
\left(0.65^{-04}\right)\end{array}$ & $\begin{array}{c}-0.48^{-03 * * *} \\
\left(0.60^{-04}\right)\end{array}$ & $\begin{array}{c}-0.46^{-03} * * * \\
\left(0.64^{-04}\right)\end{array}$ \\
\hline GROWTH & $\begin{array}{l}0.34^{-03} * * \\
\left(0.15^{-03}\right)\end{array}$ & $\begin{array}{c}0.45^{-03 * *} \\
\left(0.15^{-03}\right)\end{array}$ & $\begin{array}{c}0.23^{-03 * * *} \\
\left(0.15^{-03}\right)\end{array}$ \\
\hline Log(MIXITE) & $\begin{array}{c}-0.011^{* * * *} \\
(0.002)\end{array}$ & $\begin{array}{c}-0.011 * * * \\
(0.002)\end{array}$ & $\begin{array}{c}-0.010 * * * \\
(0.002)\end{array}$ \\
\hline SELFCONT & $\begin{array}{c}-0.07 * * * \\
(0.01)\end{array}$ & $\begin{array}{c}-0.03 * * * \\
(0.01)\end{array}$ & $\begin{array}{c}-0.08^{* * *} * \\
(0.01)\end{array}$ \\
\hline METRO & $\begin{array}{c}0.01^{* * * *} \\
\left(0.3^{-02}\right)\end{array}$ & $\begin{array}{c}0.01^{* * * *} \\
\left(0.3^{-02}\right)\end{array}$ & $\begin{array}{c}0.01^{* * * *} \\
\left(0.3^{-02}\right)\end{array}$ \\
\hline NORTH & $\begin{array}{c}0.01 * * \\
\left(0.44^{-024}\right)\end{array}$ & $\begin{array}{c}0.01^{* *} \\
\left(0.33^{-024}\right)\end{array}$ & $\begin{array}{c}0.01^{* *} \\
\left(0.43^{-024}\right)\end{array}$ \\
\hline SOUTH & $\begin{array}{l}-0.07 * * * \\
\left(0.52^{-02}\right)\end{array}$ & $\begin{array}{l}-0.08^{* * * *} \\
\left(0.37^{-02}\right)\end{array}$ & $\begin{array}{c}-0.07 * * * \\
\left(0.53^{-02}\right)\end{array}$ \\
\hline SHAREPUBB & -- & -- & $\begin{array}{c}-0.65^{-03} * * * \\
\left(0.15^{-03}\right)\end{array}$ \\
\hline COMPUBB & -- & -- & $\begin{array}{c}-0.93^{-04} * * * \\
\left(0.43^{-30}\right)\end{array}$ \\
\hline No. of obs. & 734 & 734 & 729 \\
\hline $\mathrm{R}^{2}$-adj & 0.64 & 0.65 & 0.66 \\
\hline$F$-test & $147.52 * * *$ & $154.34 * * *$ & $130.11 * * *$ \\
\hline
\end{tabular}

Note:

1. The weights are determined as the number of observations related to each of the seven underlying urban areas

2. Standard errors are given in parentheses

3. Significance is indicated by ***, ** and * for the 1,5 , and 10 percent level, respectively.

Table 8: Least squares regression analyses of the Mobility Impact Index 1991

\begin{tabular}{|c|c|c|c|}
\hline & $\begin{array}{c}\text { Model A } \\
\text { OLS }\end{array}$ & $\begin{array}{c}\text { Model B } \\
\text { WLS }\end{array}$ & $\begin{array}{c}\text { Model C } \\
\text { WLS }\end{array}$ \\
\hline \multicolumn{4}{|l|}{ INDMOB91 } \\
\hline$\beta_{\text {Bari }}$ & $0.08(0.06)$ & $0.08 * * *(0.03)$ & $0.10 * *(0.04)$ \\
\hline$\beta_{\text {Florence }}$ & $0.27 * * *(0.05)$ & $0.27 * * *(0.02)$ & $0.30 * * *(0.03)$ \\
\hline$\beta_{\text {Naples }}$ & $0.25 * * *(0.02)$ & $0.25 * * *(0.01)$ & $0.24 * * *(0.02)$ \\
\hline$\beta_{\text {Padua }}$ & $0.21 * * *(0.04)$ & $0.21 * * *(0.03)$ & $0.18 * * *(0.03)$ \\
\hline$\beta_{\text {Perugia }}$ & $0.26 * * *(0.04)$ & $0.26 * * *(0.02)$ & $0.23 * * *(0.02)$ \\
\hline$\beta_{\text {Potenza }}$ & $0.18 * * *(0.03)$ & $0.18 * * *(0.02)$ & $0.15 * * *(0.02)$ \\
\hline$\beta_{\text {Turin }}$ & $0.38 * * *(0.01)$ & $0.38 * * *(0.01)$ & $0.41 * * *(0.01)$ \\
\hline \multicolumn{4}{|l|}{ DISTANCE } \\
\hline Bari & $0.10^{-03}\left(0.32^{-03}\right)$ & $0.10^{-03}\left(0.16^{-03}\right)$ & $0.12^{-03}\left(0.16^{-03}\right)$ \\
\hline Florence & $-0.65^{-03}\left(0.53^{-03}\right)$ & $-0.65^{-03}\left(0.27^{-03}\right)$ & $-0.56^{-03}\left(0.52^{-03}\right)$ \\
\hline Naples & $-0.10^{-02} * * *\left(0.41^{-03}\right)$ & $-0.10^{-02} * * *\left(0.30^{-03}\right)$ & $-0.11^{-02 * *}\left(0.31^{-03}\right)$ \\
\hline Padua & $-0.10^{-02} * * *\left(0.41^{-03}\right)$ & $-0.11^{-02 * *}\left(0.33^{-03}\right)$ & $-0.11^{-02 * * * *}\left(0.32^{-03}\right)$ \\
\hline Perugia & $-0.42^{-03}\left(0.29^{-03}\right)$ & $-0.42^{-03 * * *}\left(0.16^{-03}\right)$ & $-0.58^{-03 * * *}\left(0.17^{-03}\right)$ \\
\hline Potenza & $-0.18^{-03} *\left(0.96^{-04}\right)$ & $-0.18^{-03} * * *\left(0.75^{-04}\right)$ & $-0.14^{-03 * *}\left(0.73^{-04}\right)$ \\
\hline Turin & $-0.96^{-03} * * *\left(0.12^{-03}\right)$ & $-0.95^{-03} * * *\left(0.17^{-03}\right)$ & $-0.78^{-03 * * *}\left(0.17^{-03}\right)$ \\
\hline
\end{tabular}




\begin{tabular}{|c|c|c|c|}
\hline & $\begin{array}{l}\text { Model A } \\
\text { OLS }\end{array}$ & $\begin{array}{l}\text { Model B } \\
\text { WLS }\end{array}$ & $\begin{array}{l}\text { Model C } \\
\text { WLS }\end{array}$ \\
\hline \multicolumn{4}{|l|}{ DENSITY } \\
\hline Bari & $0.68^{-05}\left(0.16^{-04}\right)$ & $0.68^{-05}\left(0.83^{-05}\right)$ & $0.48^{-05}\left(0.81^{-05}\right)$ \\
\hline Florence & $-0.20^{-04}\left(0.15^{-04}\right)$ & $-0.21^{-04 * * *}\left(0.76^{-05}\right)$ & $-0.24^{-04 * * *}\left(0.76^{-05}\right)$ \\
\hline Naples & $0.97^{-06}\left(0.19^{-05}\right)$ & $0.97^{-06}\left(0.14^{-05}\right)$ & $0.77^{-06}\left(0.14^{-05}\right)$ \\
\hline Padua & $-0.17^{-04}\left(0.16^{-04}\right)$ & $-0.17^{-04}\left(0.12^{-04}\right)$ & $-0.16^{-04}\left(0.14^{-04}\right)$ \\
\hline Perugia & $-0.75^{-05}\left(0.66^{-04}\right)$ & $-0.75^{-05}\left(-0.38^{-04}\right)$ & $-0.47^{-05}\left(-0.37^{-04}\right)$ \\
\hline Potenza & $-0.19^{-04}\left(0.11^{-03}\right)$ & $-0.19^{-04}\left(0.93^{-04}\right)$ & $-0.21^{-04}\left(0.90^{-05}\right)$ \\
\hline Turin & $-0.17^{-04} * * *\left(0.43^{-05}\right)$ & $-0.17^{-04} * * *\left(0.59^{-05}\right)$ & $-0.15^{-04 * *}\left(0.58^{-05}\right)$ \\
\hline \multicolumn{4}{|l|}{ RURAL } \\
\hline Bari & $0.31^{-03}\left(0.53^{-03}\right)$ & $0.31^{-03}\left(0.28^{-03}\right)$ & $0.32^{-03}\left(0.27^{-03}\right)$ \\
\hline Florence & $-0.23^{-04}\left(0.41^{-03}\right)$ & $-0.23^{-04}\left(0.20^{-03}\right)$ & $-0.17^{-03}\left(0.21^{-03}\right)$ \\
\hline Naples & $0.37^{-03} *\left(0.19^{-03}\right)$ & $0.37^{-03} * *\left(0.14^{-03}\right)$ & $0.39^{-03} * * *\left(0.14^{-03}\right)$ \\
\hline Padua & $-0.15^{-04}\left(0.28^{-03}\right)$ & $-0.15^{-04}\left(0.22^{-03}\right)$ & $-0.11^{-04}\left(0.22^{-03}\right)$ \\
\hline Perugia & $-0.33^{-03}\left(0.33^{-03}\right)$ & $-0.33^{-03 *}\left(0.19^{-03}\right)$ & $-0.20^{-03}\left(0.20^{-03}\right)$ \\
\hline Potenza & $-0.46^{-03 * *}\left(0.21^{-03}\right)$ & $-0.46^{-03 * *}\left(0.17^{-03}\right)$ & $-0.41^{-03} *\left(0.16^{-03}\right)$ \\
\hline Turin & $-0.60^{-03} * * *\left(0.83^{-04}\right)$ & $-0.60^{-03 * * *}\left(0.12^{-03}\right)$ & $-0.50^{-03 * * *}\left(0.11^{-03}\right)$ \\
\hline \multicolumn{4}{|l|}{ GROWTH } \\
\hline Bari & $0.45^{-03}\left(0.69^{-03}\right)$ & $0.45^{-03}\left(0.36^{-03}\right)$ & $0.35^{-03}\left(0.35^{-03}\right)$ \\
\hline Florence & $0.70^{-03}\left(0.63_{-03}\right)$ & $0.70^{-03} * *\left(0.31^{-03}\right)$ & $0.69^{-03}\left(0.30^{-03}\right)$ \\
\hline Naples & $0.21^{-03}\left(0.31^{-03}\right)$ & $0.21^{-03}\left(0.23^{-03}\right)$ & $0.26^{-03}\left(0.23^{-03}\right)$ \\
\hline Padua & $-0.33^{-03}\left(0.50^{-03}\right)$ & $-0.33^{-03}\left(0.40^{-03}\right)$ & $-0.21^{-03}\left(0.40^{-03}\right)$ \\
\hline Perugia & $-0.62^{-03}\left(0.89^{-03}\right)$ & $-0.62^{-03}\left(0.51^{-03}\right)$ & $-0.51^{-03}\left(0.50^{-03}\right)$ \\
\hline Potenza & $0.61^{-03}\left(0.60^{-03}\right)$ & $0.61^{-03}\left(0.47^{-03}\right)$ & $0.60^{-03}\left(0.45^{-03}\right)$ \\
\hline Turin & $0.60^{-04}\left(0.21^{-03}\right)$ & $0.59^{-04}\left(0.29^{-03}\right)$ & $0.35^{-04}\left(0.20^{-03}\right)$ \\
\hline \multicolumn{4}{|l|}{ Log MIXITE } \\
\hline Bari & $0.04(0.04)$ & $0.03 *(0.02)$ & $0.03(0.02)$ \\
\hline Florence & $-0.01(0.01)$ & $-0.01(0.01)$ & $-0.02 *\left(0.9^{-02}\right)$ \\
\hline Naples & $-0.31^{-02}(0.02)$ & $-0.32^{-02}(0.02)$ & $-0.30^{-02}(0.01)$ \\
\hline Padua & $-0.01\left(0.8^{-02}\right)$ & $-0.01 *\left(0.7^{-02}\right)$ & $-0.01\left(0.7^{-02}\right)$ \\
\hline Perugia & $-0.02(0.03)$ & $-0.02(0.08)$ & $-0.02(0.17)$ \\
\hline Potenza & $0.01(0.02)$ & $0.96^{-02}(0.02)$ & $0.64^{-02}(0.01)$ \\
\hline Turin & $-0.68^{-03}\left(0.8^{-02}\right)$ & $-0.68^{-03}\left(0.1^{-02}\right)$ & $-0.26^{-03}\left(0.11^{-02}\right)$ \\
\hline \multicolumn{4}{|l|}{ SELFCONT } \\
\hline Bari & $0.07(0.05)$ & $0.07 * * *(0.03)$ & $0.06 * *(0.03)$ \\
\hline Florence & $0.04(0.06)$ & $0.04(0.03)$ & $0.03(0.03)$ \\
\hline Naples & $-0.15 * * *(0.02)$ & $-0.15 * * *(0.02)$ & $-0.14 * * *(0.02)$ \\
\hline Padua & $0.13 * * *(0.03)$ & $0.13 * * *(0.03)$ & $0.14 * * *(0.03)$ \\
\hline Perugia & $0.09 * *(0.04)$ & $0.09 * * *(0.02)$ & $0.08 * * *(0.02)$ \\
\hline Potenza & $0.12 * * *(0.04)$ & $0.12 * * *(0.03)$ & $0.11^{* * *}(0.03)$ \\
\hline Turin & $-0.08 * * *(0.01)$ & $-0.08 * * *(0.02)$ & $-0.08 * * *(0.02)$ \\
\hline \multicolumn{4}{|l|}{ SHAREPUBB } \\
\hline Bari & & & $-0.42^{-0}\left(0.31^{-03}\right)$ \\
\hline Florence & & & $-0.54^{-03}\left(0.32^{-03}\right)$ \\
\hline Naples & & & $0.30^{-03}\left(0.32^{-03}\right)$ \\
\hline Padua & & & $0.67^{-03}\left(0.61^{-03}\right)$ \\
\hline Perugia & & & $0.13^{-02} * *\left(0.46^{-03}\right)$ \\
\hline Potenza & & & $0.75^{-03} * * *\left(0.23^{-03}\right)$ \\
\hline Turin & & & $-0.15^{-02 * * *}\left(0.29^{-03}\right)$ \\
\hline $\mathrm{N}^{\circ}$ obs. & 734 & 734 & 732 \\
\hline $\mathrm{R}^{2}$ adj & 0.72 & 0.77 & 0.79 \\
\hline$F$-test & $39.21 * * *$ & $52.04 * * *$ & $49.72 * * *$ \\
\hline Wald-test on restrictions & $\mathrm{p}<0.00 * * *$ & $\mathrm{p}<0.00^{* * *}$ & $\mathrm{p}<0.00 * * *$ \\
\hline
\end{tabular}

Notes:

1. The weights are determined as the number of observations related to each of the seven underlying urban areas.

2. Standard errors are given in parentheses.

3. Significance is indicated by $* * *, * *$ and $*$ for the 1,5 , and 10 percent level, respectively. 
Table 9: Descriptive statistics of the Mobility Impact Index per metropolitan area.

\begin{tabular}{|r|cc|cc|cc|cc|cc|c|}
\hline \multicolumn{10}{|c|}{} & \multicolumn{8}{|c|}{ Mobility Impact Index } & \multicolumn{2}{|c|}{ Minimum } & \multicolumn{2}{|c|}{ Maximum } & Increase rate \\
& \multicolumn{2}{|c|}{ Mean } & \multicolumn{2}{|c|}{ Median } & \multicolumn{2}{|c|}{ Std. dev } & $a$ & $b$ & $a$ & $b$ & $(a-b)$ \\
\hline Naple & 0.189 & 0.269 & 0.189 & 0.270 & 0.042 & 0.056 & 0.045 & 0.042 & 0.312 & 0.400 & $29.7 \%$ \\
\hline Turin & 0.287 & 0.362 & 0.287 & 0.350 & 0.049 & 0.064 & 0.121 & 0.219 & 0.453 & 0.789 & $20.6 \%$ \\
\hline Bari & 0.159 & 0.296 & 0.159 & 0.294 & 0.019 & 0.036 & 0.119 & 0.245 & 0.201 & 0.415 & $46.5 \%$ \\
\hline Florence & 0.260 & 0.371 & 0.260 & 0.354 & 0.028 & 0.056 & 0.206 & 0.294 & 0.326 & 0.556 & $29.8 \%$ \\
\hline Padua & 0.237 & 0.340 & 0.237 & 0.337 & 0.028 & 0.032 & 0.167 & 0.284 & 0.289 & 0.427 & $30.4 \%$ \\
\hline Perugia & 0.244 & 0.370 & 0.244 & 0.361 & 0.030 & 0.050 & 0.139 & 0.293 & 0.323 & 0.544 & $33.9 \%$ \\
\hline Potenza & 0.174 & 0.357 & 0.174 & 0.350 & 0.036 & 0.082 & 0.019 & 0.048 & 0.246 & 0.577 & $51.3 \%$ \\
\hline
\end{tabular}

Notes:

1. Mobility impact index calculated considering both commuters going outside and those moving within a given commune.

2. Mobility impact index calculated considering only those commuters going outside a given commune.

Table 10: Cross-section analysis of the Mobility Impact Index 1991 on the basis of the geographical position of towns and cities

\begin{tabular}{|c|c|c|}
\hline & $\begin{array}{c}\text { OLS } \\
\text { (Model A) }\end{array}$ & $\begin{array}{c}\text { OLS } \\
\text { (Model B) }\end{array}$ \\
\hline Dependent variable: & IMPACT91 & IMPACT91 \\
\hline \multicolumn{3}{|l|}{ Independent variables: } \\
\hline Intercept $\beta_{\text {North }}$ & $0.37 * * *(0.01)$ & $0.39 * * *\left(0.94^{-02}\right)$ \\
\hline$\beta_{\text {Centre }}$ & $0.25 * * *(0.02)$ & $0.25^{* * *}(0.03)$ \\
\hline$\beta_{\text {South }}$ & $0.21 * * *(0.01)$ & $0.20 * * *(0.02)$ \\
\hline \multicolumn{3}{|l|}{ DISTANCE } \\
\hline North & $-0.88^{-03} * * *\left(0.12^{-03}\right)$ & $-0.74^{-03 * * *}\left(0.12^{-03}\right)$ \\
\hline Centre & $-0.43^{-03} *\left(0.25^{-03}\right)$ & $-0.44^{-03 *}\left(0.25^{-03}\right)$ \\
\hline South & $-0.24^{-03} * * *\left(0.83^{-30}\right)$ & $-0.23^{-03 * * *}\left(0.82^{-30}\right)$ \\
\hline \multicolumn{3}{|l|}{ DENSITY } \\
\hline North & $-0.18^{-04} * * *\left(0.43^{-05}\right)$ & $-0.15^{-04 * * *}\left(0.43^{-05}\right)$ \\
\hline Centre & $-0.17^{-04} *\left(0.11^{-04}\right)$ & $-0.16^{-04}\left(0.11^{-04}\right)$ \\
\hline South & $0.16^{-05}\left(0.15^{-05}\right)$ & $0.16^{-05}\left(0.15^{-05}\right)$ \\
\hline \multicolumn{3}{|l|}{ RURAL } \\
\hline North & $-0.72^{-03 * * *}\left(0.79^{-04}\right)$ & $-0.68^{-03 * * *}\left(0.78^{-04}\right)$ \\
\hline Centre & $-0.30^{-03}\left(0.23^{-03}\right)$ & $-0.27^{-03}\left(0.25^{-03}\right)$ \\
\hline South & $-0.18^{-03}\left(0.11^{-03}\right)$ & $-0.19^{-03} *\left(0.11^{-03}\right)$ \\
\hline \multicolumn{3}{|l|}{ GROWTH } \\
\hline North & $0.47^{-04}\left(0.20^{-03}\right)$ & $0.67^{-05}\left(0.20^{-03}\right)$ \\
\hline Centre & $0.21^{-03}\left(0.52^{-03}\right)$ & $0.19^{-03}\left(0.51^{-03}\right)$ \\
\hline South & $0.46^{-03} *\left(0.24^{-03}\right)$ & $0.48^{-03} * *\left(0.23^{-03}\right)$ \\
\hline \multicolumn{3}{|l|}{ Log(MIXITE) } \\
\hline North & $-0.01 * * *\left(0.24^{-02}\right)$ & $-0.73^{-02} * * *\left(0.24^{-02}\right)$ \\
\hline Centre & $-0.01(0.01)$ & $-0.01(0.01)$ \\
\hline South & $-0.92^{-02} *\left(0.54^{-02}\right)$ & $-0.94^{-02} *\left(0.53^{-02}\right)$ \\
\hline \multicolumn{3}{|l|}{ SELFCONT } \\
\hline North & $-0.09 * * *\left(0.11^{-03}\right)$ & $-0.10 * * *(0.01)$ \\
\hline Centre & $0.07 * *(0.03)$ & $0.07 * *(0.03)$ \\
\hline South & $-0.07 * * *(0.02)$ & $-0.07 * * *(0.02)$ \\
\hline \multicolumn{3}{|l|}{ SHAREPUBB } \\
\hline North & & $-0.98^{-03 * * *}\left(0.21^{-03}\right)$ \\
\hline Centre & & $0.12^{-03}\left(0.49^{-03}\right)$ \\
\hline South & & $0.17^{-03}\left(0.22^{-03}\right)$ \\
\hline Nobs & 734 & 732 \\
\hline $\mathrm{R}^{2}$-adjusted & 0.66 & 0.68 \\
\hline$F$-test & $73.84 * * *$ & $68.16^{* * * *}$ \\
\hline Wald-test on restrictions & $197.74 * * *$ & $572.49 * * *$ \\
\hline
\end{tabular}

Notes:

1. The weights are determined as the number of observations related to each of the seven underlying urban areas. 
2. Standard errors are given in parentheses.

3. Significance is indicated by $* * * * *$ and $*$ for the 1,5 , and 10 percent level, respectively.

Table 11: Cross-section analysis of the Mobility Impact Index 1991 on the basis of the level of polycentrism of towns and cities.

\begin{tabular}{|c|c|c|}
\hline & $\begin{array}{c}\text { OLS } \\
\text { (Model A) }\end{array}$ & $\begin{array}{c}\text { OLS } \\
\text { (Model B) }\end{array}$ \\
\hline Dependent variable: & IMPACT91 & IMPACT91 \\
\hline \multicolumn{3}{|l|}{ Independent variables: } \\
\hline Intercept $\beta_{\text {Polyc }}$ & $0.22 * * *(0.02)$ & $0.22 * * *(0.21)$ \\
\hline$\beta_{\text {Metro }}$ & $0.39 * * *\left(0.88^{-02}\right)$ & $0.43 * * *(0.01)$ \\
\hline \multicolumn{3}{|l|}{ DISTANCE } \\
\hline Polycentric & $-0.33^{-03 * * *}\left(0.11^{-03}\right)$ & $-0.33^{-03 * * *}\left(0.10^{-03}\right)$ \\
\hline Metropolitan & $-0.79^{-03} * * *\left(0.13^{-03}\right)$ & $-0.45^{-03 * * *}\left(0.12^{-03}\right)$ \\
\hline \multicolumn{3}{|l|}{ DENSITY } \\
\hline Polycentric & $-0.23^{-04}\left(0.15^{-04}\right)$ & $-0.23^{-04}\left(0.13^{-03}\right)$ \\
\hline Metropolitan & $-0.18^{-04} * * *\left(0.15^{-05}\right)$ & $-0.13^{-04 * * *}\left(0.15^{-03}\right)$ \\
\hline \multicolumn{3}{|l|}{ RURAL } \\
\hline Polycentric & $-0.56^{-03} * * *\left(0.18^{-03}\right)$ & $-0.56^{-03} * * *\left(0.17^{-03}\right)$ \\
\hline Metropolitan & $-0.97^{-03} * * *\left(0.85^{-04}\right)$ & $-0.70^{-03} * * *\left(0.81^{-04}\right)$ \\
\hline \multicolumn{3}{|l|}{ GROWTH } \\
\hline Polycentric & $0.77^{-03} *\left(0.43^{-03}\right)$ & $0.77^{-03} *\left(0.39^{-03}\right)$ \\
\hline Metropolitan & $0.51^{-04}\left(0.21^{-02}\right)$ & $0.14^{-05}\left(0.19^{-03}\right)$ \\
\hline \multicolumn{3}{|l|}{ Log(MIXITE) } \\
\hline Polycentric & $0.99^{-03}\left(0.72^{-02}\right)$ & $0.99^{-03}\left(0.66^{-02}\right)$ \\
\hline Metropolitan & $0.2^{-03}\left(0.29^{-02}\right)$ & $0.53^{-03}\left(0.26^{-02}\right)$ \\
\hline \multicolumn{3}{|l|}{ SELFCONT } \\
\hline Polycentric & $-0.13 * * *(0.23)$ & $0.13 * * *(0.02)$ \\
\hline Metropolitan & $-0.14 * * *(0.13)$ & $-0.13 * * *(0.01)$ \\
\hline \multicolumn{3}{|l|}{ SHAREPUBB } \\
\hline Polycentric & & $-0.22^{-02} * * *(0.02)$ \\
\hline Metropolitan & & $0.57^{-05}(0.30)$ \\
\hline Nobs & 734 & 732 \\
\hline $\mathrm{R}^{2}-\mathrm{adj}$ & 0.45 & 0.55 \\
\hline$F$-test & $47.69 * * *$ & $60.61 * * *$ \\
\hline Wald-test on restrictions & $151.97 * * *$ & $169.27 * * *$ \\
\hline
\end{tabular}

Notes:

1. The weights are determined as the number of observations related to each of the seven underlying urban areas.

2. Standard errors are given in parentheses.

3. Significance is indicated by $* * *, * *$ and $*$ for the 1,5 , and 10 percent level, respectively. 
Figure 5: Causal chains in the explanation of mobility impact

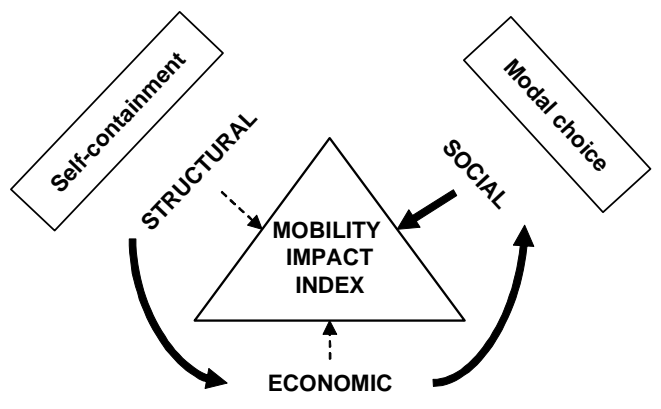

Competitiveness

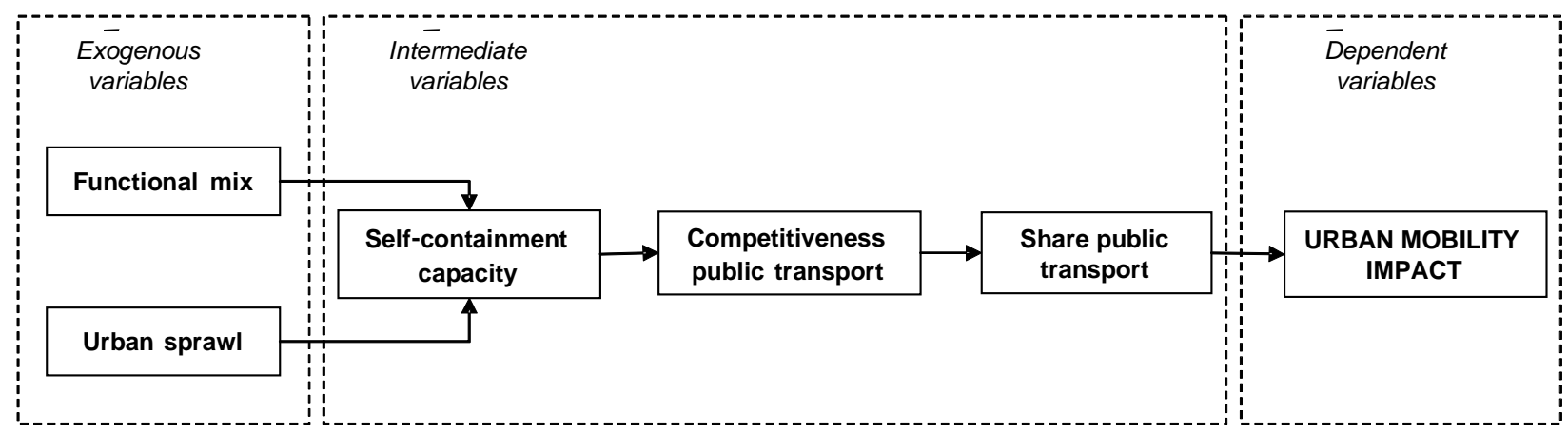

Figure 6: A general model for urban mobility impact estimates

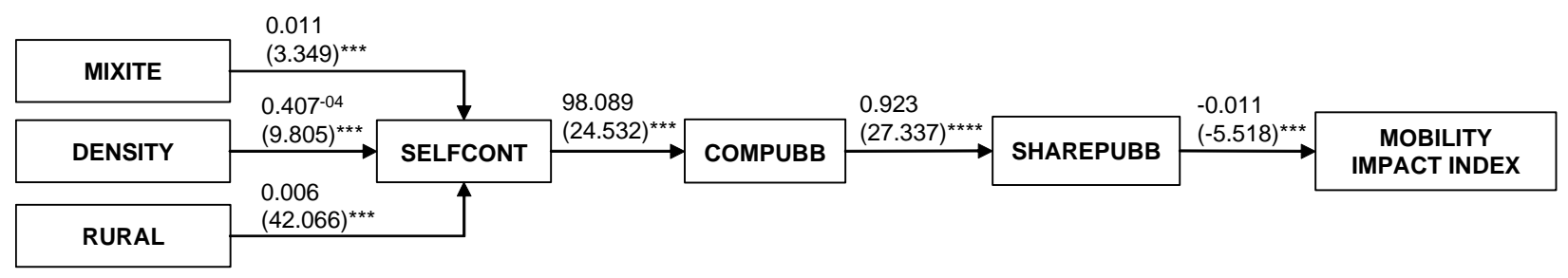

Figure 7: Estimated path analysis model for Italy.

Notes:

1. T-statistics are provided in brackets

2. Significance is indicated by $* * *, * *$ and $*$ for the 1,5 , and 10 percent level, respectively. 